\title{
Potential Applications of Phyto-Derived Ceramides in Improving Epidermal Barrier Function
}

\author{
Efrem N. Tessema ${ }^{a}$ Tsige Gebre-Mariam ${ }^{d}$ Reinhard H.H. Neubert ${ }^{a, b}$ \\ Johannes Wohlrab ${ }^{b, c}$ \\ a Department of Pharmaceutical Technology and Biopharmaceutics, Institute of Pharmacy, ${ }^{\mathrm{b}}$ Institute of \\ Applied Dermatopharmacy, and ${ }^{\mathrm{C}}$ Department of Dermatology and Venereology, Medical Faculty, Martin Luther \\ University Halle-Wittenberg, Halle (Saale), Germany; ${ }^{\mathrm{d}}$ Department of Pharmaceutics and Social Pharmacy, \\ School of Pharmacy, College of Health Sciences, Addis Ababa University, Addis Ababa, Ethiopia
}

\section{Keywords}

Dietary supplements · Glucosylceramides · Phyto-derived ceramides · Plant-derived ceramides - Skin barrier function . Skin diseases $\cdot$ Stratum corneum

\begin{abstract}
The outer most layer of the skin, the stratum corneum, consists of corneocytes which are coated by a cornified envelope and embedded in a lipid matrix of ordered lamellar structure. It is responsible for the skin barrier function. Ceramides (CERs) are the backbone of the intercellular lipid membranes. Skin diseases such as atopic dermatitis and psoriasis and aged skin are characterized by dysfunctional skin barrier and dryness which are associated with reduced levels of CERs. Previously, the effectiveness of supplementation of synthetic and animal-based CERs in replenishing the depleted natural skin CERs and restoring the skin barrier function have been investigated. Recently, however, the barrier function improving effect of plant-derived CERs has attracted much attention. Phyto-derived CERs (phytoCERs) are preferable due to their assumed higher safety as they are mostly isolated from dietary sources. The beneficial effects of phy-
\end{abstract}

\section{KARGER}

(C) 2017 S. Karger AG, Basel

E-Mail karger@karger.com

www.karger.com/spp
toCER-based oral dietary supplements for skin hydration and skin barrier reinforcement have been indicated in several studies involving animal models as well as human subjects. Ingestible dietary supplements containing phytoCERs are also widely available on the market. Nonetheless, little effort has been made to investigate the potential cosmetic applications of topically administered phytoCERs. Therefore, summarizing the foregoing investigations and identifying the gap in the scientific data on plant-derived CERs intended for skin-health benefits are of paramount importance. In this review, an attempt is made to synthesize the information available in the literature regarding the effects of phytoCERbased oral dietary supplements on skin hydration and barrier function with the underlying mechanisms.

(c) 2017 S. Karger AG, Basel

\section{Introduction}

Skin is the largest organ forming an effective barrier between the "inside" and the "outside" of the organism [1]. It is a multilayered tissue consisting of 3 primary layers: hypodermis, dermis, and epidermis [2]. The dermis

Prof. Dr. Johannes Wohlrab

Department of Dermatology and Venereology

Martin Luther University Halle-Wittenberg, Ernst-Grube-Strasse 40

DE-06120 Halle (Saale) (Germany)

E-Mail johannes.wohlrab@medizin.uni-halle.de 
is mainly composed of fibroblasts embedded in an acellular collagen/elastin matrix. The outer epidermal layer is a cellular layer mainly consisting of keratinocytes stratified into sublayers by their stage of differentiation and is responsible for the prevention of water loss from the skin and diffusion of xenobiotics into the skin $[2,3]$. The stratum corneum (SC), the outermost layer of the skin, consists of several layers of keratinized corneocytes embedded in a lipid matrix of ordered lamellar structure [4]. Ceramides (CERs) are essential components of the intercellular lipids of the SC. They play an important role in establishing and maintaining the water-retaining properties of the skin [5]. Studies have shown that the level of epidermal CERs is reduced in skin diseases such as atopic dermatitis $(\mathrm{AD})[6,7]$ and psoriasis $[8,9]$ and with increasing age $[6,10]$, resulting in defective skin barrier and skin dryness. It has been shown that direct replacement of the depleted CERs has beneficial effects in improving skin barrier function and skin hydration [11]. In an attempt to replenish natural skin CERs lost due to different skin conditions and ageing and restore the skin barrier function, CERs obtained from bovine brain and biotechnological sources have been investigated. Although the animal CER is isolated prior to the onset of bovine spongiform encephalopathy in cattle, the safety profile for cosmetic and food applications has not yet been established $[12,13]$. As an alternative, skin-similar CERs isolated from edible plants are highly safe and preferable for cosmetic and therapeutic applications. Recently, efforts are being made to deliver effective amounts of phyto-derived CERs (phytoCERs) into the skin to correct the reduced amounts of the natural skin CER in diseased and affected skin [14-16]. This review, therefore, addresses both epidermal CERs and phytoCERs, the common plant sources used in phytoCER-based formulations, oral/topical delivery of phytoCERs, and finally, opportunities, challenges, and future perspectives.

\section{Epidermis and SC}

From outside to inside, the epidermis is composed of 4 sublayers: SC, stratum granulosum, stratum spinosum, and stratum basale. The barrier function of the skin depends on the outer most layer, the SC (10-20 $\mu \mathrm{m}$ thick), which consists of several layers (18-20 layers) of keratinized corneocytes (an array of flat, polygonal, keratinfilled cells) embedded in a lipid matrix of ordered lamellar structure [17]. The corneocytes are surrounded by a densely cross-linked protein structure, the cornified en- velope (CE), which reduces the penetration of substances into the cells making the intercellular tortuous route as the main penetration pathway for xenobiotics including drugs delivered dermally or transdermally $[4,18]$. The underlying 3 layers of epidermis make up the viable epidermis (50-100 $\mu \mathrm{m}$ thick). The viable epidermis ensures the generation of the SC, i.e., the cell shedding from the SC surface (desquamation) is balanced by cell growth in the viable epidermis [19].

The SC is not only the main barrier against skin penetration of substances, but it also regulates the release of water into the atmosphere, i.e., transepidermal water loss (TEWL) [1]. The lipid regions in the SC are very important for the barrier function as they are the only continuous structure in the SC. The lipid composition of SC is unique and different from the cell membrane of living cells. The SC has nearly equimolar quantities of CERs, cholesterol, and long-chain free fatty acids (FAs) as major lipid components and cholesterol sulphate as well as cholesterol esters as minor components. Phospholipids are absent in the SC $[1,3,20]$. CERs are essential constituent of the lipid lamellae, representing nearly half of the total intercellular lipid content by weight, playing a critical role in skin health by providing a barrier and retaining the skin moisture [21, 22].

\section{Epidermal CERs and Glucosylceramides}

CERs are composed of long-chain sphingoid bases (SBs) linked to long-chain FAs through amide bonding. The SBs can be dihydrosphingosine, sphingosine, phytosphingosine, or 6-hydroxysphingosine $[23,24]$. The head groups contain hydroxyl groups capable of forming interand intramolecular hydrogen bonds [18]. The number of hydroxyl groups in the head group of the CERs appears to be substantial for the integrity of the barrier function of the SC $[25,26]$. The acyl chain of CERs also exhibits heterogeneity in terms of chain length (C16-C30), the degree of unsaturation (predominantly saturated), and hydroxylation pattern [23]. The FAs in the epidermal CERs can be non-hydroxy acids, a-hydroxy acids, $\omega$-hydroxy acids, or ester-linked $\omega$-hydroxy acids [27]. While acyl chain lengths $\mathrm{C} 24-\mathrm{C} 26$ are the predominant FAs, chain lengths of C16-C18 are found in small amounts [19]. The epidermis has unique long-chain FA, $\omega$-hydroxy FA, esterified with other FA (predominantly linoleic acid - C18:2). In addition to linoleate moiety, the $\omega$-hydroxy FA chain can also be attached to oleate or stearate moieties [28]. The chain length of $\omega$-hydroxy FA varies be-
116

Skin Pharmacol Physiol 2017;30:115-138 DOI: $10.1159 / 000464337$
Tessema/Gebre-Mariam/Neubert/ Wohlrab 


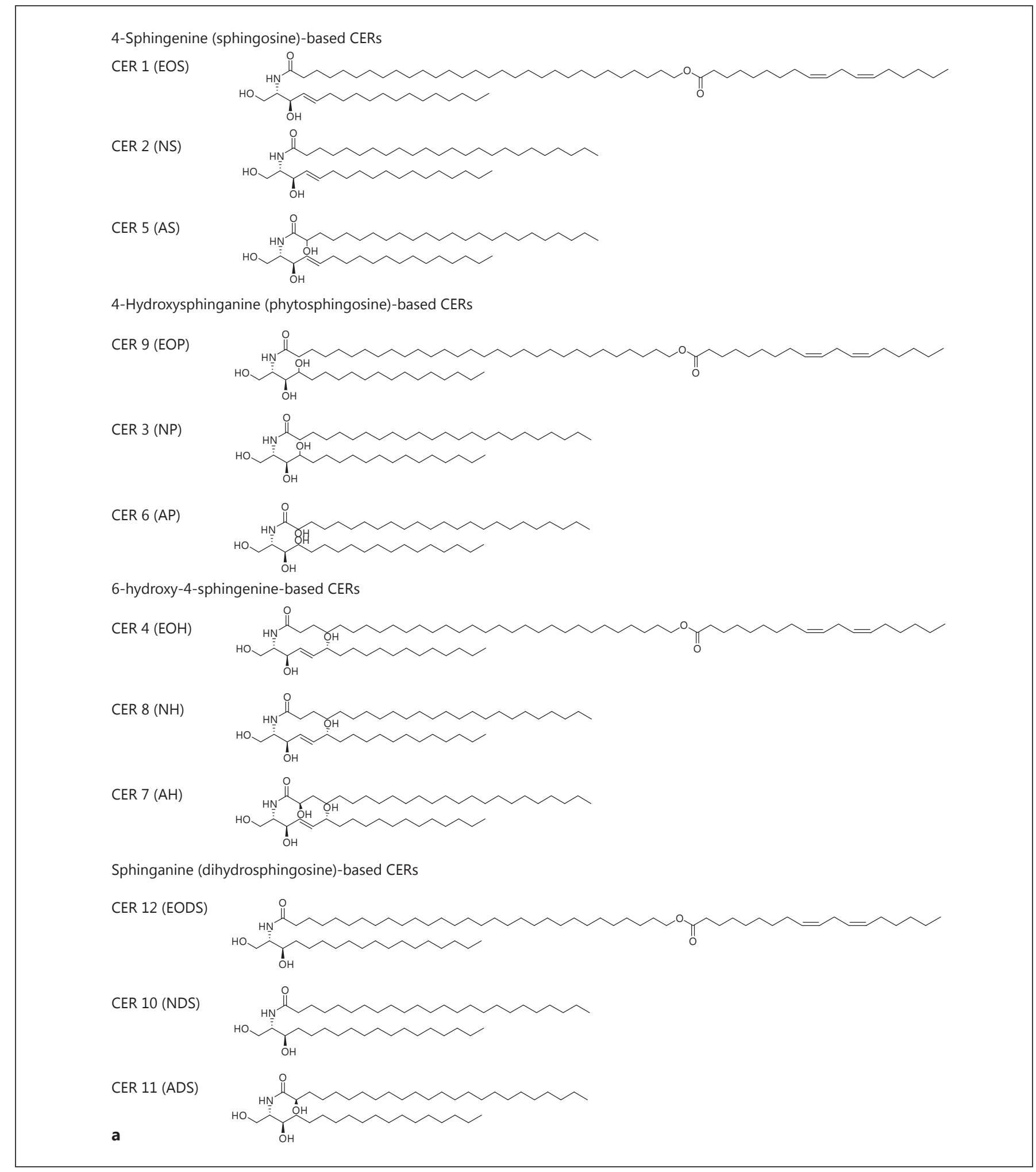

Fig. 1. Nomenclature and chemical structure of free CERs (a) and CERs covalently attached to the CE of corneocytes (b). The structures of CER classes containing $\omega$-hydroxy FA - CER (OS), CER $(\mathrm{OP}), \mathrm{CER}(\mathrm{OH})$, and CER (ODS) - are not shown. Nomenclature:
A, $a$-hydroxy FA; N, non-hydroxy FA; O, $\omega$-hydroxy FA; EO, ester-linked $\omega$-hydroxy FA; $\mathrm{P}$, phytosphingosine; $\mathrm{S}$, sphingosine; $\mathrm{H}$, 6-hydrosphingosine; DS, dihydrosphingosine.

(Figure continued on next page.)
Phyto-Derived Ceramides
Skin Pharmacol Physiol 2017;30:115-138 DOI: $10.1159 / 000464337$ 


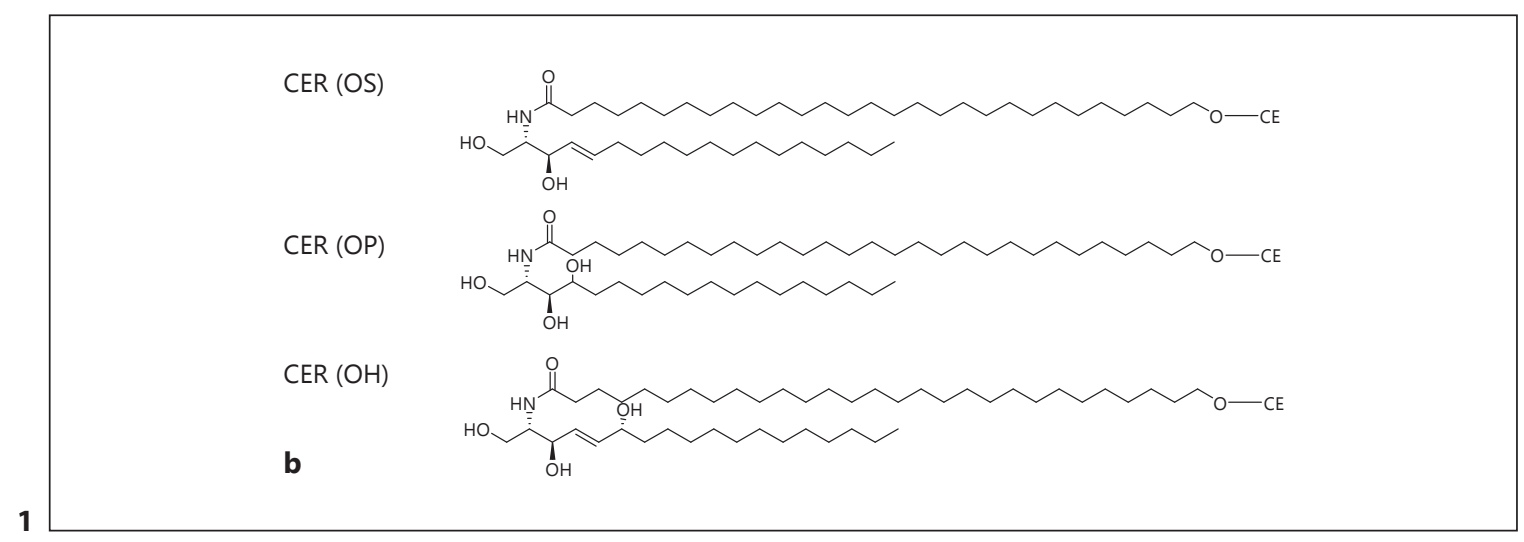

tween C28 and C32. The $\omega$-esterified acylCERs are one of the main SC lipids required for the formation of the CE $[21,29,30]$.

There are 16 free extractable CER classes in the human SC, resulting from the possible combinations of the 4 types of SBs with the 4 types of FAs, including the unique $\omega$-acylated CERs (Fig. 1a). Recently a new class of CERs with tetrahydroxyl SB have been reported [31]. Additionally, the SC has $\omega$-hydroxy CERs covalently bound to CE proteins of corneocytes (Fig. 1b) [32].

The nomenclature CER (XY) is based on acyl chain and SB components of CERs. The first letter " $\mathrm{X}$ " indicates the acyl chain: $\mathrm{N}$ for non-hydroxy FA, A for $a$-hydroxy FA, O for $\omega$-hydroxy FA, and EO for ester-linked $\omega$-hydroxy FA, and the second letter "Y" designates the SB: $S$ for sphingosine, $\mathrm{P}$ for phytosphingosine, DS for dihydrosphingosine, and $\mathrm{H}$ for 6-hydroxysphingosine, as proposed by Motta et al. [8] and Robson et al. [32]. The newly discovered CER class with tetrahydroxy SB was annotated as CER (NT) as it contains saturated non-hydroxy FA amide linked to dihydroxy dihydrosphingosine or dihydroxy sphinganine ( $\mathrm{T}$ for the 2 additional hydroxyl groups on the SB, compared to sphinganine) [31]. There is variation in the literature regarding the relative amount of the various CER species in the SC $[31,33,34]$.

SC CERs can be generated either by serine palmitoyl transferase catalyzed de novo synthesis, which converts palmitoyl-CoA and L-serine into CERs [35], or by $\beta$ glucocerebrosidase [36] and acid sphingomyelinase [37] catalyzed hydrolysis of glucosylceramides (GlcCERs) and sphingomyelin (SPM), respectively. Large quantities of GlcCER and SPM precursors are produced in the epidermis and delivered to SC extracellular lipid domains. The CER precursor metabolizing enzymes hydrolyze the GlcCER and SPM into the corresponding CER species, an important process for epidermal permeability barrier homeostasis [38-41]. It was shown that CER (NS) and CER (AS) are obtained from the hydrolysis of SPM precursors [42]. The level of epidermal CERs is, therefore, regulated by the balance between $\beta$-glucocerebrosidase, sphingomyelinase, and ceramidase (which metabolizes CERs into SBs and free FAs) [3]. The deficiency of $\beta$-glucocerebrosidase in the epidermis alters the distribution of CERs and GlcCERs and the epidermal permeability barrier [36, 43]. The impact of epidermal sphingolipids on the SC structure as well as their role in skin disorders have been reviewed by different authors [27, 44].

\section{Lipid Organization in the SC Lipid Lamellae}

The lamellar arrangement of SC lipid matrix is unique and has not yet been fully elucidated. The lipid organization showing the lipid sheets was first observed under electron microscope [45-47], and later the regular stack of lamellar sheets was characterized [48, 49]. Further understanding of the lipid organization of SC lipid lamellae was made possible by small- and wide-angle X-ray diffraction studies revealing the presence of a 13-nm lamellar phase and a long periodicity phase unique to the SC, and a 6-nm lamellar phase and a short periodicity phase in the SC lipid matrix. The presence of acylCERs was shown to be essential for the formation of the long periodicity phase [2, 50-53]. The application of neutron scattering experiments in investigating the internal membrane arrangement of bilayer structures has provided a new insight into the SC lipid organization $[26,54]$. From the neutron diffraction studies, the presence of CER (NP) and CER (AP) having 3 and 4 hydroxyl groups in the head group appeared to be crucial for the formation of the 


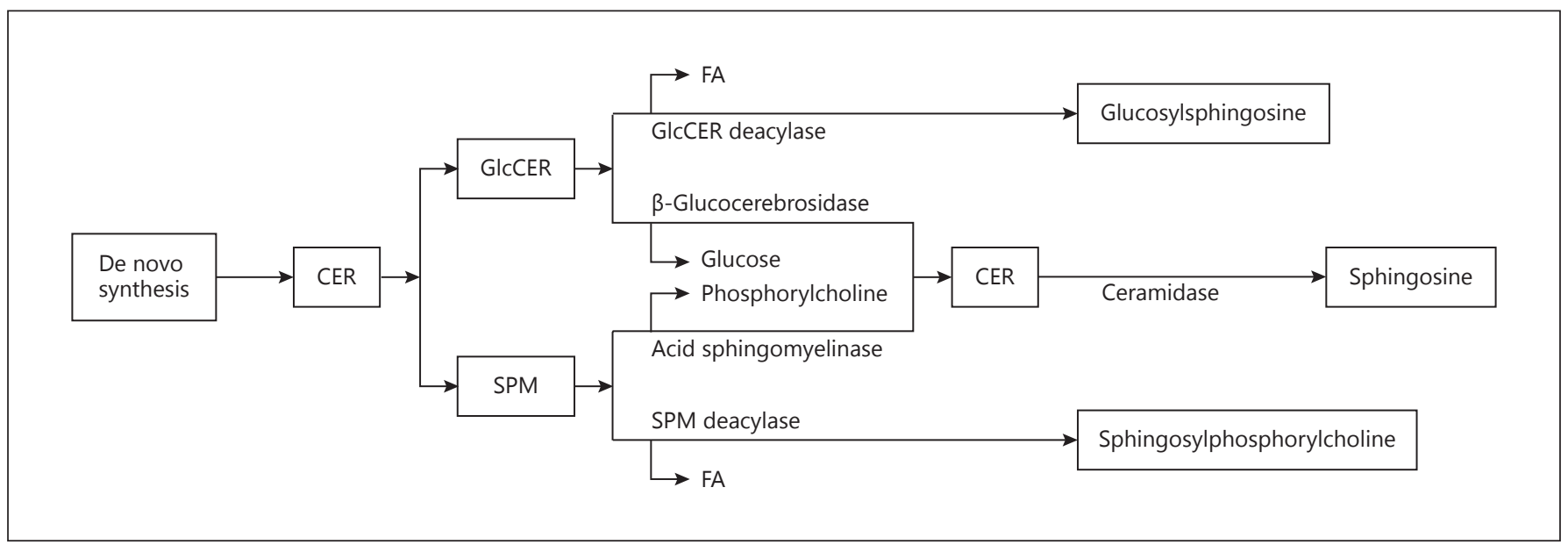

Fig. 2. Possible mechanisms for altered CER profiles in AD patients: a decrease in de novo CER synthesis; increased GlcCER and SPM deacylase activities, increased ceramidase activity; decreased sphingomyelinase activity [3].

short periodicity phase and for the integrity of the barrier function of the SC $[25,26,55]$.

Several models describing the possible structural organization of the SC lipid matrix have been proposed. In addition to those recently suggested based on neutron diffraction studies, the armature reinforcement model and the asymmetry model, the other most important models like the domain mosaic model, the single gel phase model, the stacked monolayer model, and the sandwich model have been reviewed elsewhere $[11,56]$.

\section{Skin Disorders Associated with Perturbed or Altered SC Lipids}

There are several skin diseases associated with deficiency or disturbance of SC lipids, mainly CERs including epidermal protein-bound CERs. Sahle et al. [11] summarized the common skin diseases associated with the depletion of SC lipids and the potential benefits of direct lipid replacement therapy and other approaches in treating affected, aged, or diseased skin. As phytoCERs are a potential treatment option for skin diseases with disturbed or depleted CERs, the 2 common skin diseases, AD and psoriasis, are briefly described below.

\section{Atopic Dermatitis}

$\mathrm{AD}$ is the most common chronic inflammatory skin condition associated with impaired permeability barrier function and increased TEWL. There are reports indicat-

Phyto-Derived Ceramides ing that an altered amount and composition of SC CERs represent an aetiologic factor of $\mathrm{AD}$, CER (EOS) being most affected both in lesional and non-lesional skin [6]. In addition to CER (EOS), the level of CER (NP) was found to be lower in patients with $\mathrm{AD}$ and correlated with an increased TEWL [7]. Similarly, the amounts of CER (EOS) and CER (NP) were found to be reduced in nonlesional skin of $\mathrm{AD}$ patients [57]. These findings were supported by another study which identified CER (EOH) and CER (NP) as the most significantly reduced CERs in affected skin areas of patients with $\mathrm{AD}$ [58]. In contrast to these findings, another study demonstrated that the non-lesional skin in $\mathrm{AD}$ and psoriasis and healthy skin have similar free extractable CER profiles [34].

The decreased levels of CERs in lesional and non-lesional skin were also associated with a high expression of SPM deacylase $[59,60]$ and GlcCER deacylase $[60,61]$ (Fig. 2). The ceramidase-secreting bacteria colonizing the skin of patients with $\mathrm{AD}$ were also related to the deficiency of CERs [62]. On the other hand, the activities of the 2 enzymes involved in the biosynthesis of epidermal sphingolipids, $\beta$-glucocerebrosidase, and the degradation of CERs, ceramidase, were found to be normal in atopic skin [63]. Another study showed a slight increment in the amount of sphingomyelinase in the lesional skin of $\mathrm{AD}$ patients [64].

\section{Psoriasis}

Psoriasis is a systemic chronic inflammatory disease with impaired skin barrier function. Similar to AD, the

Skin Pharmacol Physiol 2017;30:115-138 DOI: 10.1159/000464337 
Fig. 3. Chemical structure of GlcCERs showing the variation in CER backbones. The FA (which can vary in chain length and $\omega-9$ desaturation) is predominantly a-hydroxylated and is linked with a longchain base (with possible modifications: C-4 hydroxylation and C- $4 / 8$ desaturation) via amide bonding $[68,70]$.

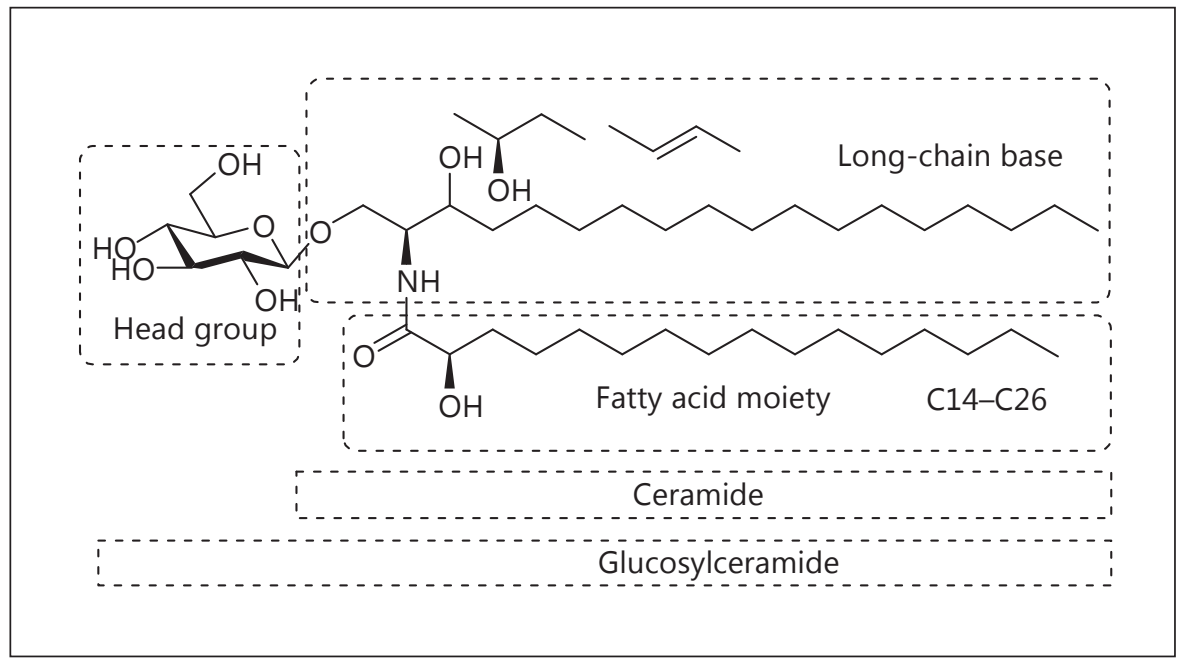

CER profile in psoriatic skin was also found to be altered. While the levels of CER (EOS), CER (NP), and CER (AP) were reduced, the amounts of sphingosine-based CERs - CER (NS) and CER (AS) - were found to be higher. The defective barrier function might be attributed to the significant decrease in CER (EOS) $[8,9]$. Although the TEWL increases in lesional psoriatic epidermis, studies have shown that there is no significant difference in terms of TEWL and water content between non-lesional psoriatic skin and normal skin $[34,65,66]$.

The impaired barrier function in psoriatic skin could also be related to the abnormal expression of enzymes involved in CER biosynthesis or degradation. Alessandrini et al. [67] indicated the possibility that disturbances in the CER generation pathways could contribute to the impairment in the psoriatic skin barrier function. The level of prosaposin, the precursor of key cofactors in sphingolipid and glycosphingolipid degradation (saposins), in the SC of psoriatic skin was found to be lower than that in normal skin. Compared to non-lesional skin, the level of sphingomyelinase in lesional skin was also decreased. Later, the authors reported a decrease in the GlcCER- $\beta$-glucosidase level in psoriatic non-lesional skin compared to normal skin [40]. A higher level of this enzyme was found in lesional psoriatic skin compared to non-lesional skin.

\section{Phyto-Derived CERs}

Plant sphingolipids are a diverse group of lipids composed of polar head groups attached to CERs which contain SBs joined with FA moieties. The structural diversity, physiological roles, and metabolism of plant sphingolipids and glycosphingolipids are well documented [68-71]. Extensive characterization of individual species in this complex and diversified class of plant lipids with powerful analytical tools led to the introduction of a new research area, sphingolipidomics [70].

Plant sphingolipids play critical roles in membrane stability and permeability, signalling, and cell regulation as well as cell-to-cell interactions $[69,71,72]$. In general, plant sphingolipids can be classified into 4 groups: glycosylceramides (GlyCERs), glycosyl inositol phosphor CERs, CERs, and free long-chain bases [70]. In the first 2 classes, polar head groups are linked to $\mathrm{C}-1$ of the $\mathrm{N}$-acyl long-chain bases with glycosidic linkage [71]. The polar head groups could be glycosyl residues, including the most abundant monohexoside (mainly glucose) and other minor di-, tri-, and tetrahexosides $[73,74]$ or phosphate-containing head groups [75]. Galactose-containing sphingolipid is rarely detected or reported in plants. In plants, compared to monohexoside CERs, oligo glycosylceramides are not well characterized as they exist in minute amounts [69].

Fig. 4. Structures of common $\mathrm{C} 18$ higher plant and mammalian SBs showing the variation at C4 of SBs: C4-saturated, C4-desaturated, C4-hydroxylated, and C4-desaturated/C6-hydroxylated. The names and shorthand designations are according to Karlsson [180]: d, dihydroxylated; $t$, trihydroxylated; the following numbers indicate the number of carbon atoms (18) and double bonds $(0,1$, 2). Recently skin CERs with 4-hydroxyl SB have been reported [31]. The C4-double bond is primarily in the trans (E) configuration, whereas the C8-double bond is either cis $(\mathrm{Z})$ or trans $(\mathrm{E})$ configuration.

(For figure see next page.)
Tessema/Gebre-Mariam/Neubert/ Wohlrab 
Higher plant-type SBs

Sphinganine (d18:0) (dihydrosphingosine)<smiles>CCCCCCCCCCCCCCC[C@@H](N)[C@H](N)CO</smiles>

8-E-Sphingenine $(\mathrm{d} 18: 1)^{(8 \mathrm{E})}$<smiles>CCCCCCCCC/C=C/CCCC[C@@H](O)[C@H](N)CO</smiles>

4-E-Sphingenine $(\mathrm{d} 18: 1)^{(4 \mathrm{E})}$<smiles>CCCCCCCCCCCCC/C=C/[C@@H](O)[C@H](N)CO</smiles>

4-E,8-E-Sphingadienine (d18:2) ${ }^{(4 E, 8 E)}$<smiles>CCCCCCCCC/C=C/CC/C=C/[C@@H](O)[C@H](N)CO</smiles>

4-E,8-Z-Sphingadienine (d18:2) $)^{(4 E, 8 Z)}$<smiles>CCCCCCCCC/C=C/CC/C=C/[C@@H](O)[C@H](N)CO</smiles>

4-Hydroxysphinganine (t18:0) (phytosphingosine)<smiles>CCCCCCCCCCCCCC[C@@H](O)[C@H](O)[C@H](N)CO</smiles>
4-Hydroxy-8-E-sphingenine (t18:1) ${ }^{(8 z)}$<smiles>CCCCCCCCC/C=C/CCC[C@@H](O)[C@H](O)[C@H](N)CO</smiles>

4-Hydroxy-8-Z-sphingenine (t18:1) ${ }^{(8 \mathrm{E})}$<smiles>CCCCCCCCC/C=C/CCC[C@@H](O)[C@H](O)[C@H](N)CO</smiles>

Mammalian-type SBs

\section{C4-saturated}

Sphinganine (d18:0) (dihydrosphingosine)<smiles>CCCCCCCCCCCCCCCC(O)C(N)CO</smiles>

\section{C4-desaturated}

4-Sphingenine (d18:1) (sphingosine)<smiles>CCCCCCCCCCCCC/C=C/C(O)C(N)CO</smiles>

C4-hydroxylated

4-Hydroxysphinganine (t18:0) (phytosphingosine)<smiles>CCCCCCCCCCCCC/C=C/C(O)C(N)CO</smiles>

C4-desaturated/C6-hydroxylated<smiles>CCCCCCCCCCCCC(O)/C=C/CC(N)CO</smiles> 
In plants CERs are mainly found in glycosylated form as a component of the plasma membrane and tonoplast of plant cells [76]. The most abundant class of sphingolipids in plant tissue are mono-GlcCERs, which are mostly characterized by a double bond at position 8 on the sphingoid residues and a-hydroxy FAs [77]. Figure 3 shows the chemical structure of plant GlcCERs which comprises a hydrophobic CER part and a hydrophilic head group.

\section{Structural Comparison of Plant and Epidermal CERs}

Although the basic chemical structure of plant and skin CERs is similar, there are differences in chain length, hydroxylation pattern, and degree of unsaturation of the SB and FA moieties. In general, phytoCERs exhibit substantial structural diversity [76]. The SB profile of plants is more diversified than that of mammalian SBs. Previous investigations on plant sphingolipids have identified several dihydroxy and trihydroxy SBs with 1 or 2 double bonds depending on the type of desaturase enzymes present in the plants. In addition to $\Delta^{4}$ sphingolipid desaturase, plants have $\Delta^{8}$-sphingolipid desaturase resulting in cis (Z)- and trans (E)- isomers of $\Delta^{8}$-unsaturated SBs [78]. Figure 4 depicts possible modifications - hydroxylation or (E)-desaturation at C-4 and (E/Z)-desaturation at C-8 - of typical C18 SBs of plant and mammalian CERs.

In plant GlcCERs, 8E/8Z isomers of 4,8-sphingadienine $\left(\mathrm{d} 18: 2^{\Delta 4,8}\right)$, 4-hydroxy-8-sphingenine $\left(\mathrm{t} 18: 1^{\Delta 8}\right)$, and 8 -sphingenine $\left(\mathrm{d} 18: 1^{\Delta 8}\right)$ represent the dominant bases [71]. SBs with trace quantities include sphinganine (d18:0) and 4-hydroxysphinganine (t18:0). GlcCERs containing sphingatrienine (d18:3) [79] and minor amounts of C17 and C19 SBs [80] have also been reported in some plants. While the naturally occurring dihydroxy bases have D-erythro configuration, trihydroxy bases have D-ribo configuration $[68,71]$.

The structural variation of skin CERs results from possible combinations of the 4 types of SBs with the 4 types of FAs [81]. The SBs of human epidermal CER species differ from plant SBs in the number/position of desaturation. The skin SBs have desaturation at C-4 (d18:1 $\left.{ }^{\Delta 4}\right)$, while plants contain C-8 desaturation in addition to C-4 in a typical plant SB [71]. The SBs which are found in relatively higher amounts in skin CERs, sphingosine and 4-hydroxysphinganine, have been detected in smaller amounts in plants [82-85].
In plant GlcCERs, the FAs bound to the SBs have a chain length of C14-C26 atoms and are mostly saturated and $\alpha$-hydroxylated [86]. The principal FAs are C16-, C20-, C22-, and C24-saturated a-hydroxy FAs. Low amounts of $\omega$-9-monounsaturated very long-chain FAs (C22-C26), mostly a-hydroxynervonic acid (C24:1) in the leaf GlcCERs, are also found in plants [86-88]. On the other hand, skin CERs contain non-hydroxy, a-hydroxy or $\omega$-hydroxy FAs, the latter having a chain length up to C32 and mostly ester-linked with unsaturated FA [5]. In plants $\omega$-hydroxy FAs containing GlcCERs have not been yet found. The head group similarities (having 3-4 hydroxyl groups) of plant-derived CERs and mammalian CERs - such as CER (NP) and CER (AP) - suggest the potential application of phytoCERs in improving the skin barrier function of diseased and/or aged skin.

Generally, GlcCERs obtained from seed, leaf, and root tissues display different SB and FA profiles. Lynch and Dunn [71] have attempted to summarize the SB and hydroxy FA profiles of soybean [89], wheat grain [84], rye leaf [90], maize leaf [82], and spinach leaf [83] GlcCERs. While dihydroxy SBs and hydroxy FAs saturated by C16$\mathrm{C} 20$ - the predominant one being $\alpha$-hydroxypalmitic acid (h16:0) - are enriched in seed tissues, trihydroxy bases and very long-chain (C20-C26) saturated and $\omega-9$ monounsaturated hydroxy FAs occur abundantly in leaf tissues [71, 87].

\section{Structural Profiling of Plant GIcCERs}

Liquid chromatography tandem mass spectrometry (LC-MS/MS) is a powerful, specific, and sensitive technique for qualitative as well as quantitative analyses of GlcCERs [80]. While the LC (either normal or reversed phase) allows separation of intact GlcCER molecules in a complex mixture, the tandem MS uniquely identifies the various molecular species of GlcCERs [91]. The structural identification is based on the unique molecular decomposition pattern of the GlcCERs (dehydration, deglucosylation, and N-deacylation), i.e., precursor-product ion mass transfer at a specific retention time (Fig. 5) [79, 92-94]. Previously, either electrospray ionization or atmospheric pressure chemical ionization interfaces have been used for the LC-MS-based qualitative and quantitative analysis of sphingolipids [77, 92, 94-97].
Tessema/Gebre-Mariam/Neubert/ Wohlrab 
Fig. 5. Characteristic fragmentations of a representative plant GlcCER containing d18:2 (4,8-sphingadienine) coupled with h16:0 ( $\alpha$-hydroxypalmitic acid) under positive ionization mode. Product ions: (1) loss of 1 mole of water; (2) loss of 1 mole of water and glucose; (3) loss of 1 mole of water, glucose and fatty acyl group, and (4) loss of 2 moles of water, glucose and fatty acyl group. Designation on the SB: d (dihydroxy SB), 18 (number of carbon atoms of $\mathrm{SB}), 2$ (number of desaturations on the SB). Designation on the FA: h (hydroxy FA), 16 (the number of carbon atoms of FA), and 0 (number of desaturations on the FA).

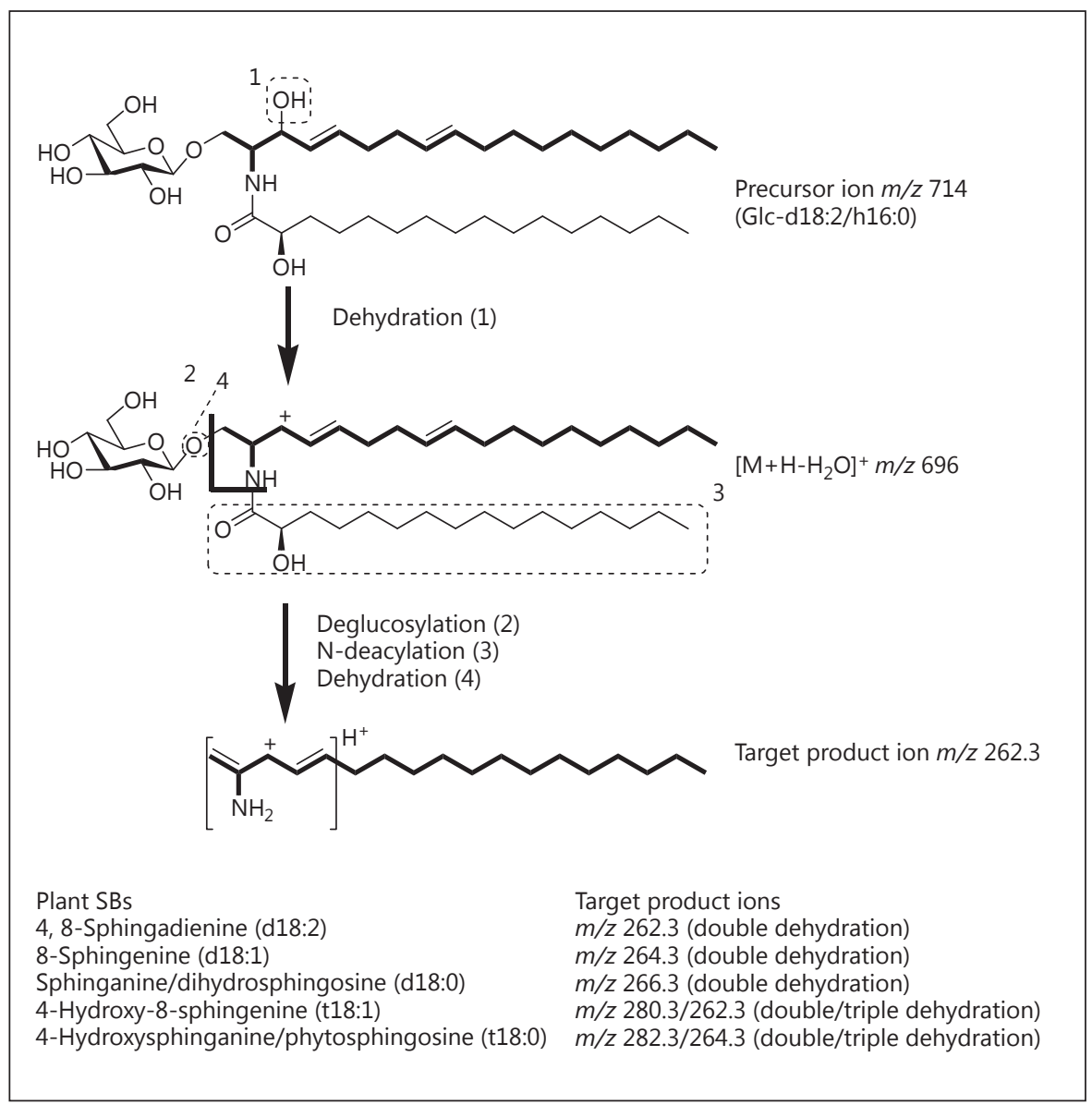

\section{Plants Commonly Used in PhytoCER-Based Formulations}

Studies have shown that a proper amount of epidermal CERs is necessary to maintain healthy skin. As plant-derived CERs are chemically similar to epidermal CERs, phytoCER-based skincare products can aid in skin moisturization and protective barrier reinforcement. Oral as well as topical delivery of phytoCERs can either enhance the endogenous epidermal lipid-synthetic capability [16, 98] or replace depleted skin CERs in some skin conditions and ageing [99]. These CERs are naturally found in many cereal, tuber, and legume dietary sources such as wheat $[74,77,84]$, rice $[73,80,100]$, corn $[80,101]$, potato and sweet potato [96], soybean [77, 102], and konjac [103, 104]. Although CERs were originally derived from soybean and bovine sources, currently there are many types of plant-based CERs available on the market.

In this section, in addition to the popular commercial plant sources of CERs used in dietary supplements and cosmeceutical formulations meant for skin barrier improvement (rice and wheat germ extracts), other potential plants such as potato, sweet potato, corn, and konjac will be addressed. As plants contain a large amount of glycosphingolipids, mainly GlcCERs, emphasis will be given to the chemical compositions (FAs and SBs) of GlcCER species of these plants.

\section{Rice-Derived GlcCERs}

In recent years glycosphingolipids extracted from rice (Oryza sativa) are widely used in nutritional and cosmeceutical supplements. Fujino and Ohnishi [105] described the isolation and chemical analysis of CER and monoGlyCER species in rice bran. Later they characterized the chemical structure of free and glycosylated (mono-, di-, tri-, and tetra-) CERs isolated from bran and endosperm of rice grains [73]. In both free and glycosylated CERs, non-hydroxy and $\alpha$-hydroxy FAs exist, the principal type being $\alpha$-hydroxy FAs (C14-C28). These FAs are combined with dihydroxy and/or trihydroxy C18 SBs (Tables 
Table 1. Fatty acid composition in different plant sources

\begin{tabular}{|c|c|c|c|c|c|c|c|c|c|c|c|}
\hline \multirow[t]{3}{*}{ Fatty acids } & \multicolumn{11}{|c|}{ Composition, \% } \\
\hline & \multicolumn{3}{|l|}{ wheat } & \multicolumn{3}{|l|}{ rice } & \multirow{2}{*}{$\begin{array}{l}\text { sweet } \\
\text { potato } \\
\text { tuber }\end{array}$} & \multirow{2}{*}{$\begin{array}{l}\text { potato }^{a} \\
\text { tuber }\end{array}$} & \multicolumn{2}{|l|}{ maize } & \multirow{2}{*}{$\begin{array}{l}\text { kidney } \\
\text { bean }\end{array}$} \\
\hline & grain & flour & leaf & bran & endosperm & leaf & & & commercial $^{\mathrm{b}}$ & leaf & \\
\hline $16: 0$ & - & - & - & - & - & - & 6 & $6-10$ & - & - & 4.6 \\
\hline $16: 1$ & - & - & - & - & - & - & 1.5 & $0.1-9$ & - & - & 0.7 \\
\hline h14:0 & 0.2 & 0.2 & - & $<0.1$ & $<0.1$ & - & - & - & - & - & 0.8 \\
\hline h16:0 & 39.1 & 40.2 & 8.4 & 0.4 & 0.2 & 0.1 & 78 & $76-86$ & 6 & 3.9 & 58.2 \\
\hline h18:0 & 7.5 & 4.5 & 0.9 & 5.9 & 5.2 & 1.4 & 2 & $2-2.5$ & 17 & 5.0 & 0.3 \\
\hline h20:0 & 43.7 & 44.1 & 7.0 & 30.9 & 42.4 & 42.3 & 1 & 0.1 & 39 & 29.6 & 0.5 \\
\hline h21:0 & 0.6 & 0.4 & 1.7 & 1.5 & 0.4 & 1.7 & 0.2 & - & - & 0.5 & - \\
\hline h22:0 & 3.1 & 3.7 & 17.2 & 14.7 & 12.4 & 31.5 & 4 & $0.2-1$ & 13 & 31.9 & 5.6 \\
\hline h22:1 & - & - & 3.5 & - & - & - & - & - & - & - & - \\
\hline h23:0 & 0.2 & 0.1 & 5.2 & 3.5 & 1.2 & 1.7 & 0.6 & $0.1-0.5$ & - & 0.7 & 1.3 \\
\hline h24:0 & 2.5 & 5.4 & 23.5 & 30.3 & 29.1 & 20.2 & 3 & $1-2$ & 22 & 27.3 & 23.3 \\
\hline h24:1 & 1.1 & & 23.1 & - & - & - & - & - & - & - & - \\
\hline h25:0 & 0.2 & 0.1 & $<0.1$ & 4.2 & 1.4 & 0.2 & 1 & $0.1-0.3$ & - & 0.4 & 0.9 \\
\hline h26:0 & 0.4 & 0.5 & 3.1 & 7.3 & 7.2 & 0.9 & 1 & $0.2-0.5$ & 3 & 0.7 & 1.2 \\
\hline h26:1 & - & - & 2.2 & - & - & - & - & - & - & - & - \\
\hline Others & 1.4 & 0.8 & - & 1.3 & 0.5 & - & 4.2 & $0.6-3.9$ & - & - & 2.6 \\
\hline Ref. No. & 84 & 74 & 87 & 73 & 73 & 87 & 97 & 97 & 102 & 87 & 110 \\
\hline
\end{tabular}

The data reported here are expressed as \% of total GlyCERs. Only the composition of mono-GlcCER has been considered. ${ }^{\text {a }}$ The range represents the results of the different potato species. ${ }^{b}$ Commercial maize GlcCER-rich preparation from Nippon Flour Mills Co. Ltd. (Atsugi, Japan).

$1,2)$. The major GlcCER species in rice consists of 4,8sphingadienine acylated with hydroxyarachidic acid (h20:0)/hydroxylignoceric acid (h24:0). The sugar analyses of GlyCERs of rice grain indicated glucose and mannose as the only constituent saccharides.

\section{Wheat-Derived GlcCERs}

GlcCERs derived from wheat germ and wheat germ oil have been on the market in the U.S and other countries over the last few decades. Structural investigation of sphingolipids in wheat grain identified both free and glycosylated (mono-, di-, tri- and tetra-) CERs [84]. The principal FA components in free CERs are C24 and C22 a-hydroxy FAs. The CER portions of glycosylated CERs mainly consist of hydroxypalmitic (h16:0) and hydroxyarachidic (h20:0) acids. The other FAs, non-hydroxy (the predominant species being palmitic, stearic, and lignoceric acids) and 2,3-dihydroxy acids (only as component of free CERs), were found in minute quantities. The structural identification of GlcCERs isolated from wheat flour also showed similar results [74]. The major wheat GlcCERs, therefore, comprised of 8-sphin- genine acylated with hydroxypalmitic acid/hydroxyarachidic acid (Tables 1-3).

\section{Potato- and Sweet Potato-Derived GlcCERs}

GlcCERs derived from potato (Solanum tuberosum L.) and sweet potato (Ipomoea batatas (L.) Lam.) have been incorporated in a number of dietary supplements intended for skin barrier improvement. Bartke et al. [96] have analysed the CERs and GlcCERs of these plants using RPHPLC-ESI-MS/MS. The predominant SB of GlcCERs isolated from potatoes and sweet potatoes was found to be 4,8 -sphingadienine, representing about $80-85 \%$ of the long-chain bases of all detected GlcCERs. It was also shown that $\alpha$-hydroxypalmitic acid (h16:0) is the principal FA of GlcCERs of these plants. The major GlcCER species detected (about 80\%) was Glc-d18:2-h16:0.

\section{Konjac-Derived GlcCERs}

Konjac (Amorphophallus konjac K. Koch) is very popular cooking supplement in Japan and a rich source of GlcCERs. Konjac tuber-derived GlcCERs have been commercialized as dietary supplements for dry skin and are 
Table 2. Sphingoid base composition in different plant sources

\begin{tabular}{|c|c|c|c|c|c|c|c|c|c|c|c|c|}
\hline \multirow{2}{*}{$\begin{array}{l}\text { Sphingoid } \\
\text { bases }\end{array}$} & \multicolumn{12}{|c|}{ Composition (\%) } \\
\hline & $\begin{array}{l}\text { kidney } \\
\text { bean }\end{array}$ & $\begin{array}{l}\text { wheat } \\
\text { grain }\end{array}$ & $\begin{array}{l}\text { wheat } \\
\text { flour }\end{array}$ & $\begin{array}{l}\text { wheat } \\
\text { leaf }\end{array}$ & $\begin{array}{l}\text { rice } \\
\text { bran }\end{array}$ & $\begin{array}{l}\text { rice } \\
\text { endosperm }\end{array}$ & $\begin{array}{l}\text { rice } \\
\text { leaf }\end{array}$ & $\begin{array}{l}\text { sweet } \\
\text { potato }\end{array}$ & potato $^{a}$ & maize $^{\mathrm{b}}$ & $\begin{array}{l}\text { maize } \\
\text { leaf }\end{array}$ & konjac \\
\hline $\mathrm{d} 18: 0$ & 0.2 & 9 & 7.6 & 0.2 & 0.3 & 1.0 & 0.1 & - & - & 1 & $<0.1$ & - \\
\hline $\mathrm{d} 18: 1^{\mathrm{D} 4 \mathrm{E}}$ & $<0.1$ & 1 & 1.2 & & 2.5 & 5.9 & - & - & - & 3 & - & 0.6 \\
\hline $\mathrm{d} 18: 1^{\mathrm{D} 8 \mathrm{E}}$ & 2.7 & 24 & 25.3 & 1.3 & 1.8 & 2.2 & 0.3 & - & - & - & 0.2 & 3.8 \\
\hline $\mathrm{d} 18: 1^{\mathrm{D} 8 \mathrm{Z}}$ & 2.7 & 47 & 42.6 & 3.2 & 1.8 & 2.2 & 0.3 & 4.5 & $2.7-3.9$ & - & 1.0 & 3.8 \\
\hline $\mathrm{d} 18: 2^{\mathrm{D} 4 \mathrm{E} / 8 \mathrm{E}}$ & 60.1 & 2 & 8.5 & 5.2 & 16.5 & 34.6 & 11.5 & 86.0 & $91.0-94.0$ & 17 & 17.3 & 54.0 \\
\hline $\mathrm{d} 18: 2^{\mathrm{D} 4 \mathrm{E} / 8 \mathrm{Z}}$ & 17.3 & 13 & 12.4 & 9.4 & 53.3 & 40.6 & 34.3 & 86.0 & $91.0-94.0$ & 53 & 55.7 & 54.0 \\
\hline $\mathrm{t} 18: 0$ & 0.3 & 1 & 0.5 & 0.9 & 3.3 & 1.2 & 0.8 & - & - & 2 & 0.4 & 1.4 \\
\hline $\mathrm{t} 18: 1^{\mathrm{D} 8 \mathrm{E}}$ & 11.0 & 1 & 0.5 & 6.9 & 6.1 & 2.8 & 3.1 & 9.5 & $3.0-5.2$ & 2 & 1.6 & 40.2 \\
\hline $\mathrm{t} 18: 1^{\mathrm{D} 8 \mathrm{Z}}$ & 8.5 & 2 & 1.4 & 72.9 & 16.2 & 11.9 & 49.6 & 9.5 & $3.0-5.2$ & 22 & 23.8 & 40.2 \\
\hline d18 base & 80.2 & 96 & 97.6 & 19.3 & 74.4 & 84.1 & 46.5 & - & - & 74 & 74.2 & 58.4 \\
\hline t18 base & 19.8 & 4 & 2.4 & 80.7 & 25.6 & 15.9 & 53.5 & - & - & 26 & 25.8 & 41.6 \\
\hline Ref. No. & 110 & 84 & 74 & 82 & 73 & 73 & 82 & - & - & 102 & 82 & 104 \\
\hline
\end{tabular}

The data reported here are expressed as \% of total GlyCERs. Only the composition of mono-GlcCERs has been considered. ${ }^{\text {a The }}$ range represents the results of the different potato species. ${ }^{b}$ Commercial maize GlcCER-rich preparation from Nippon Flour Mills Co. Ltd. (Atsugi, Japan).

Table 3. Different plants and their predominant GlcCER species

\begin{tabular}{|c|c|c|c|c|c|}
\hline Plants & Scientific name & Family & Tissue & Predominant GlcCER species & Ref. No. \\
\hline Rice & Oryza sativa & Poaceae & $\begin{array}{l}\text { Seed bran, } \\
\text { endosperm }\end{array}$ & $\mathrm{d} 18: 2 / \mathrm{h} 20: 0$ and $\mathrm{d} 18: 2 / \mathrm{h} 24: 0$ & 73,80 \\
\hline Wheat & Triticum aestivum $\mathrm{L}$. & Poaceae & Grain, flour & $\mathrm{d} 18: 1^{\Delta 8} / \mathrm{h} 16: 0$ and $\mathrm{d} 18: 1^{\Delta 8} / \mathrm{h} 20: 0$ & $74,77,84$ \\
\hline Sweet potato & Ipomoea batatas (L.) Lam. & Convolvulaceae & Tuber & d18:2-h16:0 & 97 \\
\hline Potato & Solanum tuberosum L. & Solanaceae & Tuber & d18:2/h16:0 & 97 \\
\hline Konjac & Amorphophallus konjac & Araceae & Tuber & $\mathrm{d} 18: 2 / \mathrm{h} 18: 0$ & 108 \\
\hline Beet & Beta vulgaris L. & Amaranthaceae & Fibre & d18:2/h16:0 & 111 \\
\hline Maize & Zea mays L. & Poaceae & Commercial $^{\mathrm{a}}$ & d18:2/h20:0 and d18:2/h24:0 & 102 \\
\hline Kidney bean & Phaseolus vulgaris L. & Fabaceae & Seed & $\mathrm{d} 18: 2 / \mathrm{h} 16: 0$ & 110 \\
\hline Soybean & Glycine max & Fabaceae & Seed & $\mathrm{d} 18: 2 / \mathrm{h} 16: 0$ & 77 \\
\hline
\end{tabular}

${ }^{\text {a }}$ Commercial maize GlcCER-rich preparation from Nippon Flour Mills Co. Ltd. (Atsugi, Japan).

available from various commercial sources $[14,104,106]$. GC-MS analysis of SBs obtained from the hydrolysis of konjac tuber-derived GlcCERs revealed that 4,8-sphingadienine and 4-hydroxy-8-sphingenine are the major sphingoid moieties [103] (Table 2). The principal GlcCER constituent has 4,8-sphingadiene amide linked with hydroxy stearic acid (h18:0) [107].

\section{Maize-Derived GlcCERs}

The CER moieties of maize (Zea mays) GlcCERs predominantly constitute C18, C20, and C24 a-hydroxy
FAs linked with 4E/8Z-sphingadienine [101]. The sphingadienine makes up about $70 \%$ of the total maize SBs $[101,108]$. In addition to 4-hydroxy-8-sphingenine, maize GlcCERs were found to have sphingatrienine (d18:3) acylated to hydroxy FAs (C16-C24), indicating the existence of the triene type of SB in higher plants [79].

As can be seen from Table 3, the predominant GlcCER species in most of the plants have 4,8-sphingadienine/4sphingenine and hydroxypalmitic acid/hydroxyarachidic acid as SB and FA components, respectively.

Skin Pharmacol Physiol 2017;30:115-138 DOI: $10.1159 / 000464337$ 


\section{Oral Delivery of PhytoCERs}

In the early 1990s a large number of topical skin care products containing CERs were formulated and marketed by cosmetic companies for the treatment of skin conditions associated with ageing including fine lines, wrinkles, and dryness. Most of these products were creams and lotions which are claimed to have skin hydration and renewal effects. Later, in 1997, Japanese nutraceutical companies started to formulate and market oral phytoCER-based nutritional supplements and beauty drinks [109]. Currently, both phytoCER-based ingestible dietary supplements and CER-based topical skin-moisturizing products are widely distributed on the market in USA and other countries. In this section, reports on the effects of oral phytoCERs on skin barrier function, the pharmacokinetic aspects of oral phytoCERs, and the possible underlying mechanisms for barrier function improvement are summarized. In addition, some marketed and patented phytoCER-based products are briefly introduced.

\section{Effect of Oral PhytoCER-Based Dietary Supplements on Skin Barrier Function}

In addition to in vitro studies, the beneficial effects of oral intake of plant-derived CERs for skin hydration and skin barrier reinforcement have been established in several studies involving animal models $[14,15,110,111]$ as well as human subjects $[14,106,109,112]$. These studies were mostly conducted on detergent- or tape-strippedperturbed human skin and/or hairless mouse skin [14, 113 ] or on skin with diet-induced $\mathrm{AD}$-like symptoms in animal models $[114,115]$. The skin barrier function is commonly measured by the TEWL value which is a marker for the inside-outside barrier. It can be measured by different devices including Tewameter ${ }^{\circledR}$ (Courage + Khazaka, Cologne, Germany) [14, 112], VapoMeter (Delfin, Kuopio, Finland) [16], Evaporimeter ${ }^{\circledR}$ (Asahi Biomed, Yokohama, Japan) [15], Meeco ${ }^{\circledR}$ Water Analyzer (Meeco, Warrington, PA, USA), or other similar devices [116].

A number of investigations have been carried out to demonstrate the effects of phytoCER-based dietary supplements on the skin barrier function, skin hydration and appearance (reduction of wrinkles and fine lines), SC lipid composition, and enzyme activities. Tsuji et al. [15] examined the effect of dietary GlcCERs derived from rice and maize on the maintenance and recovery of skin barrier function in hairless mice, respectively. The mice were fed with a special skin-damaging diet (HR-AD) which increases TEWL and reduces SC flexibility. The TEWL of GlcCER-fed hairless mouse skin was found to be significantly reduced, and the SC flexibility was also improved. Feeding of a maize GlcCER diet after acute barrier perturbation by tape stripping also enhanced the recovery of skin barrier of the mice.

Recently, the protective effect of orally administered beet (Beta vulgaris) GlcCERs against diet-induced (HRAD) skin barrier impairment (increased TEWL and scratching behaviour, dry skin with erythema) in hairless mice was investigated [111]. The dietary supplement prevented the increase in TEWL and cumulative scratching time in mice fed with the special diet. Yeom et al. [110] used oxazolone-induced chronic irritant contact dermatitis in mouse model skin to investigate the beneficial effect of oral administration of soybean GlcCERs on inflammatory dry skin. The orally administered GlcCERs had an anti-inflammatory action, and reduced itching and the suppression of inflammation was attributed to the inhibition of cytokine production. GlcCERs also suppressed the SC dehydration and repaired the skin barrier function.

Clinical studies have also supported the skin-moisturizing and skin barrier recovery effects of phytoCERs. A randomized, double-blind placebo-controlled trial was conducted on women with dry skin to investigate the moisturizing effect of dietary supplement containing wheat extract enriched with GlcCERs and digalactosyldiglycerides (DGDG) [109]. According to the finding, there was a significant increase in skin hydration with improved associated clinical signs (itching, squamae, roughness, and redness). Ingestion of konjac GlcCERs has also shown positive effects in $\mathrm{AD}$ patients as well as healthy volunteers. It has been reported that oral intake of konjac GlcCERs decreased the TEWL in AD patients (14 patients with mild to moderate atopic eczema were involved) [112], and improved skin symptoms (including TEWL reduction) and reduced skin allergic responses in children with $\mathrm{AD}$ ( 50 children with moderate $\mathrm{AD}$ were involved in the study) [106]. In another study, oral intake of konjac GlcCERs reduced the TEWL of hairless mouse skin (rough skin induced by sodium dodecyl sulphate, SDS) and in healthy human subjects (in a randomized double-blind study of 100 individuals with high TEWL in the cheeks) [14]. The effects of beet GlcCERs on skin elasticity in female volunteers with dry skin and fibronectin production in human dermal fibroblasts were investigated. The beet GlcCERs promoted fibronectin synthesis but had no effect on fibroblast proliferation or collagen syn-
126

Skin Pharmacol Physiol 2017;30:115-138 DOI: $10.1159 / 000464337$
Tessema/Gebre-Mariam/Neubert/ Wohlrab 
thesis [117]. Unlike most of the other plant GlcCERs (rice, corn, and konjac), beet GlcCERs did not induce significant improvements in TEWL. The anomaly was explained by the differences in the SB and FA profiles of the plant GlcCERs as well as the existence of other unidentified lipid components in the beet CERs which might alter the skin condition.

The foregoing studies support the beneficial effects of oral intake of plant GlcCERs and their potential complementary and alternative therapeutic applications in the restoration and maintenance of skin barrier function. However, more detailed and comprehensive studies are still required to document the clinical efficacy of oral phytoCERs in diseased and aged skin.

\section{Digestion, Absorption, and Uptake by Keratinocytes of Oral PhytoCERs}

Despite the fact that there are several reports describing the beneficial effects of orally administered phytoCER-based dietary supplements, the pharmacokinetic aspect of oral phytoCERs has not been well investigated. Early studies have indicated the presence of enzymes catalyzing the cleavage of SPM into CERs (sphingomyelinase) and CERs into sphingosine and FAs (ceramidase) in the small intestinal tract $[118,119]$. In 1969, a research study done by Nilsson [120] suggested that the metabolism of dietary GlcCERs does not occur in the intestinal contents, but instead occurs in the mucosal cells after absorption. After 2 decades, a study conducted on isolated intestinal loops of mice demonstrated that metabolism of dietary SPM occurs in all regions of the intestine, and biologically active metabolites are slowly taken up by mucosal cells [121]. The authors proposed that some part of the sphingolipid passes into the large intestine, and the transportation of intact SPM as well as its metabolites from the intestine to other organs is inefficient. Another study supported the finding that digestion of SPM is extended over the entire small intestine, mainly in the middle and lower parts, and was found to be associated with the distribution of the alkaline sphingomyelinase. The lower small intestine and colon are exposed to SPM and sphingolipid metabolites for a longer time [122].

Earlier investigations have also suggested that lactasephlorizin hydrolase, a small intestinal disaccharidase, exhibits glycosylceramidase activity in the intestine and plays an important role in the digestion of dietary glycolipids $[123,124]$. In addition, other studies have provided

Phyto-Derived Ceramides evidence on the existence of ceramidase in intestinal content $[125,126]$. A decade ago, Kono et al. [127] demonstrated that neutral ceramidase encoded by the Asah2 gene is a key enzyme for the metabolism of dietary sphingolipids. The dietary sphingolipids are taken up by enterocytes after being catabolized on the brush border membrane of the small intestine by neutral ceramidase. It was also shown that dietary SPM is not absorbed intact, but sphingosine produced from neutral ceramidase hydrolysis of CER is well absorbed [128].

Sugawara at al. [108] investigated the digestion of maize GlcCERs in rats to understand the digestive fates of common SBs (d18:2 $2^{\Delta 4 \mathrm{E} / 8 \mathrm{Z}}$ and $\left.\mathrm{d} 18: 2^{\triangle 4 \mathrm{E} / 8 \mathrm{E}}\right)$ in higher plants. After oral administration, the maize GlcCERs were cleaved into CERs and free SBs in the gastrointestinal tract of rats. The research group further evaluated the uptake of sphingadienine by enterocytes using Caco-2 cells, derived from human colonic carcinoma, as a model of intestinal epithelial cells. Although the digestibility of maize and mammalian GlcCERs appeared the same, the metabolic fate of plant-derived sphingoids within enterocytes differed from that of sphingosine. Unlike sphingosine, the uptake of sphingadienine into the body was found to be inhibited by a P-glycoprotein, suggesting the poor absorption of the plant-derived sphingadienine from the digestive tract. The authors, in another study, found similar results supporting the finding that there is a selective efflux of plant SBs by P-glycoprotein, resulting in selective absorption of sphingosine from dietary sphingolipids in the gastrointestinal tract [129].

In earlier studies sphingadienine has been identified in plasma [130], red blood cells of humans [131], and mouse brains [132]. However, plant-derived SBs desaturated at C8 were not detected in mammalian tissues, indicating that sphingadienine obtained from daily dietary sources is poorly incorporated and reconstructed into complex sphingolipids in tissues [129]. Besides, the predominant plant-derived SB, 4E/8Z-sphingadienine, was not detected in the mouse skin after ingestion of maize-derived GlcCERs [12].

Previous studies have also identified sphingolipid metabolites in thoracic lymph fluid of maize GlcCER-infused rats, indicating the absorption of dietary GlcCERs into lymph fluid $[133,134]$. Some CER species and the predominant GlcCER species of maize, Glc-d18:2/h20:0, were only detected in the lymph fluid of GlcCER-infused rats but not in control rats [133]. The results suggested that part of plant sphingolipid metabolites, perhaps CER, is absorbed through the intestinal epithelial cells. According to the authors' assumption, the dietary GlcCER

Skin Pharmacol Physiol 2017;30:115-138 127 
is degraded into $\mathrm{CER}, \mathrm{SB}$, and FA, which in turn controls the external and internal sphingolipid levels in the lymph fluid. However, further investigations have to be carried out to explain the effect of change in lymph fluid sphingolipid level on the blood components. Besides, another study reported that the principal SB of maize GlcCERs, $4 \mathrm{E} / 8 \mathrm{Z}$-sphingadienine, was found in the lymph of GlcCER-fed rats in its free form and as a constituent of CER, recovered at a very low concentration [134]. The results demonstrated that the plant GlcCERs are only slightly absorbed from the intestine (attributed to the low intestinal digestion capacity, according to the authors) and are incorporated into CER structures in the intestinal cells. The low recovery of the SB might also be attributed to the P-glycoprotein efflux of 4,8-sphingadienine $[108,129]$. It was also indicated that the possibility of reutilizing the intact form of SBs in the tissues is very low [134].

Generally, the mechanism by which exogenous GlcCERs are absorbed and transported to the skin has not been full elucidated. Further pharmacokinetic studies supporting the effects of oral phytoCER in skin barrier reinforcement are needed.

\section{Mechanisms Underlying Skin Barrier Improvement}

Despite the structural differences between plant and skin CERs, the beneficial effects of dietary plant GlcCERs have been shown. The few foregoing studies suggested that the absorbed metabolites of ingested GlcCERs might have been distributed to the skin to exhibit their beneficial effects. However, the underlying mechanisms by which orally administered GlcCERs improve the skin barrier function remain largely unknown. Below are some of the proposed mechanisms.

\section{Increase Epidermal CERs}

Ishikawa et al. [133] studied the changes in the epidermal sphingolipid levels with dietary GlcCERs in mice. The epidermal sphingolipid levels were found to be significantly higher in the GlcCER-fed mice than in the control mice. The total level of CERs in both SC and living cells and the amounts of GlcCER and SPM in the living cells were higher than the control group. However, it was unclear whether or not the observed increase in epidermal CER is associated with de novo synthesis. Different authors have pointed out the possible mechanisms by which oral administration of plant GlcCERs could increase epidermal CERs. These include direct localization and utilization of absorbed dietary CER in the epidermis without any metabolic conversion, utilization of exogenous GlcCER metabolites by keratinocytes to construct their own sphingolipids, or induction of the production of skin CERs by metabolites [14, 15, 99, 135].

Ueda et al. [99] examined the absorption, distribution, and excretion of CER, the major metabolite of GlcCER in the gastrointestinal tract, after oral administration of radioactive ${ }^{3} \mathrm{H}$-CER to rats. The results demonstrated the gradual distribution of some of the CER into the dermis and then to the epidermis, suggesting the involvement of the orally administered CER or its metabolite(s) in the skin barrier improvement. Later on they demonstrated the distribution of SB in the skin; the absorbed sphingosine was distributed to the skin and then transferred from the dermis to the epidermis [136]. Some part of the sphingosine was distributed unchanged, and the other part was involved in the biosynthesis process generating GlcCERs and CERs.

Considering the various reports on dietary sphingolipids, it is unlikely that the skin reutilizes the intact dietary CERs and/or SBs as major constituents of SC lipid lamellae $[12,137]$. Some of the reasons include the low recovery of the plant-specific SB in the lymph (indicating poor intestinal absorption of dietary GlcCERs) [134], the conversion of the majority of dietary sphingosine into palmitic acid during intestinal absorption [119-121], a very low level of absorption of plant-specific SB (explained by a selective efflux of plant SBs by P-glycoprotein) $[108,129]$, not detecting the plant-specific SB (4,8-sphingadienine) in mammalian tissues [12], the similar skin barrier improving effect of GlcCERs and SPM [137], and the fact that the amount of GlcCERs ingested is too small to directly localize in the skin and enhance CER levels [103].

\section{Inhibiting Inflammatory Cytokine Production}

The other possible mechanism stated was the inhibition of inflammatory cytokine production by oral GlcCERs. The production of interleukin-1 $\alpha$, an inflammatory cytokine that exacerbates skin roughness, in hairless mouse skin was shown to reduce after oral GlcCER administration, and this might have contributed to the improvement of skin barrier function [14]. In another study, oral GlcCER administration suppressed mRNA expression of the proinflammatory cytokines interleukin$1 \beta$ and interleukin- 6 in a chronic irritant contact dermatitis mouse model of inflammation [110]. These results suggest beneficial effects of dietary GlcCERs in inflammatory skin diseases.
Tessema/Gebre-Mariam/Neubert/ Wohlrab 
Expression of Genes Involved in the Maintenance and Formation of SC: Epidermal Transglutaminases, Tight Junction, and CE-Related Genes

Epidermal SC is composed of CE and intercellular multilamellar lipids. The CE, an essential structure for barrier function, consists of involucrin, loricrin, small proline-rich proteins and other proteins covalently crosslinked by epidermal transglutaminases (TGases) [138]. Besides, the maturation of CE in the SC is also important in proper barrier formation [139]. On the other hand, the tight junction proteins in mammalian epidermis also contribute to the various skin functions including barrier formation [140]. These facts led to the hypothesis that the genes involved in the maintenance and formation of the SC (expression of genes associated with CE and tight junction protein formation) could be activated by exogenous GlcCERs or their metabolites [141].

Hasegawa et al. [142], using UVB irradiation-induced barrier-perturbed hairless mouse skin, demonstrated the positive effect of konjac GlcCERs on the skin barrier function and the level of TGase-1 gene expression. In addition to TEWL reduction, a significant increase in TGase-1 gene expression was observed in the skin of GlcCER-fed mice. SBs also enhanced the formation of CE of cultured normal human keratinocyte cells by stimulating the production of involucrin. These results suggest that plant GlcCER metabolites might have contributed to the skin barrier improvement. The authors also indicated the possibility that the level of CERs covalently bound to the $\mathrm{CE}$ of corneocytes might change upon oral administration of GlcCERs.

Ideta et al. [141], in an attempt to elucidate the molecular mechanism behind the barrier-improving effect of orally administered GlcCERs, evaluated mRNA expression of SDS-induced barrier-perturbed dorsal skin of hairless mice using microarray analysis. Oral GlcCERs significantly increased the expression of genes associated with $\mathrm{CE}$ and tight junction formation. The TEWL, which was increased in SDS-treated control mice, was inhibited in GlcCER-fed mice. The maintenance and recovery of skin barrier effects of the GlcCERs were attributed to their SB metabolites.

Another work aimed at investigating the influence of dietary GlcCERs (konjac) on the expression and localization of the tight junction component transmembrane protein, claudin-1, in UVB-irradiated mouse epidermis revealed the induction of claudin-1 [143]. Phytosphingosine also increased the expression of claudin-1 mRNA in cultured keratinocytes, suggesting that the enhanced tight junction formation could be induced by GlcCER

Phyto-Derived Ceramides metabolites and could at least partly contribute to the improvement of tight junction permeability function.

Expression of Genes Related to CER de novo Synthesis

Recently, the effects of the principal SBs of konjac GlcCERs, 4,8-sphingadienine and 4-hydroxy-8-sphingenine, on the expression of genes related to de novo synthesis of CER was examined in normal human epidermal keratinocytes using real-time quantitative PCR [103]. The change in the CER levels in a 3-dimensional (3D) human skin model after treating with SBs was also studied. The SBs were found to activate the expression of genes related to de novo CER synthesis and increased the production of CERs - CER (EOS), CER (NS), and CER (NP). These effects were not observed with GlcCERs and 4-sphingenine, indicating that the barrier-improving effect of GlcCERs is mediated by the plant SBs.

In another report, the transcriptional activities of peroxisome proliferator-activated receptors (PPARs), ligand-activated transcription factors that regulate lipid and glucose metabolism, increased by phytoCERs (C4hydroxylated), whereas CER (C4-desaturated) and dihydroCER did not change the PPAR activity. The PPAR isoform concerned with keratinocyte differentiation, PPAR- $\beta$, was the most intensively stimulated isoform by the phytoCER [144]. The differential response to the various CER species could suggest that the metabolites derived from plant GlcCERs, not animal-derived CERs, regulate the expression of PPAR-targeted genes.

\section{Activation of Epidermal Sphingolipid Metabolizing Enzymes}

Recently, a new insight explaining the mechanism of the skin barrier improving effect of dietary sphingolipids has been reported. Duan et al. [137] studied the changes in CER synthases in the epidermis after oral administration of GlcCERs (from maize) and SPM (from porcine brain) using diet-induced AD-like and tape-stripped injured skin mouse models. The dietary sphingolipids improved the recovery of the damaged skin barrier by activating the CER synthases in the epidermis. The SBs were suggested to upregulate the CER synthesis. Nevertheless, the dietary GlcCERs and SPM did not affect the expression of epidermal $\beta$-glucocerebrosidase and sphingomyelinase.

Takatori et al. [145] investigated the changes in gene expression in hairless mouse skin after oral administration of GlcCERs using DNA microarray analysis and attempted to compare the changes in the whole skin, dermis, and epidermis. Based on their findings they sug-

Skin Pharmacol Physiol 2017;30:115-138 DOI: 10.1159/000464337 
gested, in addition to the genes involved in skin lipid metabolism, the need to investigate changes in the expression of other genes and to correlate the changes of expression of certain genes in the dermis and epidermis, as well as in the whole skin.

\section{PhytoCER-Based Preparations and Oral Marketed Products}

Currently, a wide variety of PhytoCER-based "antiageing" (which are claimed for the treatment of ageing problems such as fine lines, wrinkles, and dryness) and skincare products are widely available on the market as dietary supplements in the USA and other countries. Most of these dietary supplements are available on Amazon and other online sellers in the form of capsules. These products are mostly formulated from limited sources of commercially available phytoCERs. The 2 popular commercial sources of CERs for marketed dietary supplements and cosmetic products are wheat germ and rice extracts. There are also products containing potato and sweet potato CERs.

Most of the phytoCER-based formulations are encapsulated into veggie capsules and composed of vitamins essential for the maintenance of healthy skin (including vitamins $\mathrm{A}, \mathrm{C}, \mathrm{D}$, and $\mathrm{E}$ ). The skin has antioxidants like vitamin $\mathrm{C}$ and $\mathrm{E}$ which prevent $\mathrm{UV}$-induced skin oxidative damage i.e., skin photo-ageing and photo-carcinogenesis [146]. To support the endogenous antioxidant system and to enhance the skin protection from oxidative stress, most of the marketed phytoCER products contain vitamin C and E [147]. Many of the products also contain fillers, lubricants, and glidants, although there are products free of these additives. There are also oil extractbased formulations consisting of phytoCERs, such as Lipowheat ${ }^{\mathrm{TM}}$ oil extract, wheat germ oil, and wheat-derived Ceramosides ${ }^{\mathrm{TM}}$ oil blend, which are encapsulated into liquid capsules/soft gelatin capsules. In addition to the vitamins and antioxidants, the softgel fill material may also contain hydrophilic matrix (mostly polyethylene glycol).

There are commercial phytoCER-enriched preparations available on the market for cosmetic and dietary supplements meant for skin applications. Most of these phytoCERs-enriched preparations are patented and are available in different forms including oils and powders; the common ones are briefly described below.

ORYZA CER-PCD ${ }^{\circledR}$. Oryza CER has been tested and sold in Japan since 2001 and is manufactured by Oryza Oil \& Fat Co. Ltd., Japan. CER-PCD ${ }^{\circledR}$ is a patented food- grade brown powder extracted and refined from rice bran and rice germ which can be formulated into different skin care products (including capsules, tablets, and liquids). It contains a minimum of $3 \%$ glycosphingolipids (the principal GlcCER being contained 4,8-sphingadienine acylated with a-hydroxy arachidic acid) and is composed of $40 \%$ rice extract and $60 \%$ cyclodextrin. It was claimed to have a superior moisturizing effect compared to other sources like wheat-derived CERs [148].

Lipowheat ${ }^{T M}$. This is a patented product enriched with wheat-derived polar lipids (CERs and GlcCERs, 8-10\%, and DGDG, 50-55\%) marketed by HITEX, Vannes, France. It also contains other lipids such as phospholipids (30-35\%), triglycerides, and sterols [149-151]. The wheat extract rich in CERs and DGDG has been developed in 2 forms: Lipowheat ${ }^{\mathrm{TM}}$ oil and Lipowheat ${ }^{\mathrm{TM}}$ powder. The latter is obtained after a second extraction of the oil with acetone (which removes the triglycerides). The beneficial effects of oral Lipowheat ${ }^{\mathrm{TM}}$ have been supported by clinical studies [109]. This CER-enriched wheat extract was first marketed in 1997 in Japan. Before 1997 there were no plant-derived CERs available on the market [109]. Only synthetic and bovine-derived CERs were available.

Cennamide ${ }^{T M}$. This comprises vegetal CERs manufactured and patented by ENNAGRAM, Pantin, France, and is composed of GlcCERs and DGDG extracted from wheat. It is available in different forms: wheat lipids at $15 \%$ CERs, water-dispersible powder at 50\% CERs, and water-soluble emulsion at 5\% CERs.

Ceramosides $^{T M}$. This is a patented complex of polar lipids purified from wheat flour extract produced by SEPPIC, Paris, France. It is composed of complex of GlcCERs and DGDG and is guaranteed to be gluten free as the purification process removes all traces from the phytoCER extracts. It is used for neutraceutical and dietary supplements. It is claimed to have skin-moisturizing and "antiageing" nutritional ingredients for nutri-cosmetic formulations. It is available as oil ( $>15 \%$ phytoCERs and $>15 \%$ DGDG) and powder ( $>50 \%$ phytoCERs and $>40 \%$ DGDG) forms for softgel and hard gelatin capsule/tablet applications, respectively [152].

Konjac CER. This is extracted from konjac tubers and has long been used as a foodstuff by the Japanese as well as Chinese people. It is commercially available from various sources including Unitika Ltd. (Kyoto, Japan), Nagara Science Co. Ltd. (Gifu, Japan), and Biopurify Phytochemicals Ltd. (Chengdu, China) [14, 104, 106]. The highly purified preparations are enriched with GlcCERs and are commercialized for cosmetic and dietary applications.
Tessema/Gebre-Mariam/Neubert/ Wohlrab 


\section{Topical Delivery of PhytoCERs}

Attempts have been made to treat skin dryness and skin barrier dysfunction associated with depletion and/or disturbance of SC lipids. One of the approaches is direct replacement of the depleted lipids to repair the barrier function and improve skin hydration [11]. With the recent understanding of the pathophysiological processes of skin diseases, different topical formulations containing CERs, pseudo-CERs, or agents correcting the depleted CERs have been produced [153], in addition to skin moisturizers. Studies have shown that CER-dominant emollients [154158], CER [36, 159], and pseudo-CER containing topical products [160-162] have beneficial effects in the management of skin diseases related to perturbation of SC lipids. However, many of these cosmetic products have limited published data to document their cutaneous efficacy [153].

The CERs used in lipid-based formulations and related researches are either synthetic versions of the natural skin CER analogues [26, 54, 163, 164] and pseudo-CERs [35], or isolated from bovine brain [37] or produced biotechnologically. Although skin-similar CERs are found in plants, little effort has been made to investigate the potential applications of topically administered phytoCER formulations for diseased, aged, and affected skin.

\section{Controlled Delivery of PhytoCERs into the SC}

The CERs meant to replenish the depleted CERs in the SC have to be delivered deep into the stratum granulosum-SC interface as the SC lipid organization into lipid bilayers takes place at the interface $[11,19,165]$. One of the challenges in topical replenishment of depleted CERs is the poor penetration of CERs into the SC from conventional formulations. Most of the studies supporting the positive effects of topical formulations containing synthetic CERs/pseudo-CERs and animal-based CERs [166, 167] were unable to confirm the penetration of the CERs into the SC and deeper layers of the skin. Different formulation strategies improving the poor solubility and facilitating the permeation of CERs deep into the SC, including colloidal formulations, have been designed and evaluated $[164,168-170]$. Considering the fact that phytoCERs are structurally similar to SC CERs, the difference being desaturation at position 8 of SBs or chain length or hydroxylation of the FAs, one can assume that phytoCERs can be delivered into the SC and can potentially stabilize SC lipid lamellae. However, in vitro as well as in vivo studies are needed to investigate the permeation of plant-derived

Phyto-Derived Ceramides
CERs into the SC and to understand the influences of those structural variations on the stabilization of the SC lipid bilayer as well as lipid biosynthesis in the skin.

There are different possibilities once the phytoCERs are delivered into the SC: either the CERs directly localize in the SC, integrate with natural skin CERs and contribute to the skin barrier function, or increase the production of endogenous CERs, thereby improving the barrier function. If the exogenous CERs are directly localized in the SC, further in vitro and in vivo studies are required for a better understanding of the molecular arrangement of the phytoCERs in the SC lipid matrix, their integration with endogenous skin CERs, and their role in stabilizing the bilayer structure of the SC and improving its barrier function.

Neutron diffraction $[25,26]$ and X-ray diffraction $[53$, 163 ] studies are the 2 commonly used in vitro studies used to investigate the molecular organization of SC lipids. The impact of the phytoCERs on the nanostructure of SC lipid model membranes mimicking SC lipid organization has to be investigated using these instrumental methods. Furthermore, the roles of phytoCERs in epidermal barrier function have to be studied in animal models as well as human skin (healthy and diseased).

The limited scientific evidence showing the positive effects of phytoCER-based topical products on skin barrier and hydration improvement could be partly attributed to the fact that the phytoCERs predominantly exist in glycosylated form. As the CERs are meant for controlled delivery into the SC, an optimum method of hydrolysis, either chemically or enzymatically, has to be developed to investigate the effect of free CERs in barrier function improvement.

\section{Delivery of PhytoCER Precursors into the Viable Epidermis}

There are 2 biosynthesis pathways generating the major SC CERs: glucocerebrosidase catalyzed hydrolysis of GlcCERs and sphingomyelinase catalyzed hydrolysis of SPM (Fig. 2) [39, 42]. An alternative strategy to increasing the CER level in the skin and improving barrier function could be effectively delivering the CER precursors GlcCERs and SPM to the viable epidermis, assuming that the exogenous CER precursors will be metabolized by epidermal enzymes.

As an alternative to human and animal skin, 3D reconstructed human epidermis models such as EPISKIN ${ }^{\mathrm{TM}}$ [171], TEST SKIN ${ }^{\mathrm{TM}}$ [103] and LabCyte EPI-MODEL $[172,173]$ were developed for skin metabolic and other

Skin Pharmacol Physiol 2017;30:115-138 131 
epidermis-related studies. The structure of these cultured skin models is histologically/morphologically similar to the in vivo human epidermis. The LabCyte EPI-MODEL was used to investigate the changes in CER level in cultured skin after the application of topical formulations containing CER precursors. Tokudome et al. [172] evaluated the increase in CER (NS) level in a cultured skin model after the application of SPM-based liposomes to the LabCyte EPI-MODEL. The application of liposomes significantly increased the amount of CER (NS) in the cultured skin model. The same research group, in another study, also evaluated the effect of the size of liposomes in enriching the CER level in a 3D model membrane [173]. In the later study it was found that the levels of CERs which are not derived from SPM - CER (NP) and CER (AP) - significantly increased, especially when the small-sized liposomes were applied. This finding suggests that the increase in the CER level in the membrane is not only attributed to the enzymatic reactions, but that other mechanisms might be involved as well.

Shimoda et al. [16] demonstrated the effects of ricederived GlcCERs on the changes of epidermal CER and GlcCER in mice, after oral dosing, as well as in a human epidermal equivalent. The findings indicated an increase in the level of epidermal CER (EOS), a decrease in the amounts of GlcCERs (accompanied with enhanced glucocerebrosidase and GlcCER synthase expressions), and improved TEWL after oral dosing of GlcCER, suggesting an epidermal GlcCER metabolism enhancing effect of oral GlcCERs. On the other hand, the rice-derived GlcCER increased the level of CER (EOS), CER (NS), and GlcCER (accompanied with enhanced expression of GlcCER synthase but not glucocerebrosidase) in the human epidermal equivalent. The authors suggested further investigation to clarify the discrepancy of the effect of GlcCERs on epidermal enzyme expression in mice and in the human epidermal equivalent. The in vitro study also showed an increase in the expression of the epidermal maturation markers TGase and involucrin, which may contribute to the formation of CE and hydration of the epidermis. The same epidermal model was later used to investigate the increase in CER levels - CER (NS), CER (NP), CER (AS), and CER (AP) - after the application of liposomes containing ricederived GlcCERs [98]. The results showed an increase in the level of CER (AS) after the application of GlcCERbased liposomes in a dose-dependent manner. The other CERs did not show significant changes. Besides, the inhibitor for $\beta$-glucocerebrosidase, conduritol B epoxide, reduced the amounts of CERs significantly. These findings suggest that the topically delivered CER precursors obtained from plants might have enhanced the natural lipid-synthetic capability of the epidermis and probably corrected the reduced amounts of CERs in the skin.

Plant GlcCERs have also been incorporated into topical cosmetic products to investigate their effects on skin hydration and barrier function. Asai and Miyachi [174] evaluated the skin-moisturizing effects of topically applied skin moisturizers containing rice-derived phytoCERs and orally administered corn-derived CERs on human healthy volunteers. The topical moisturizers and the oral CERs increased the water content in the SC and suppressed the TEWL. On the other hand, Shimada et al. [175] studied the inhibitory effect of topically applied maize-derived GlcCER on UVA-induced wrinkle formation and epidermal thickness in hairless mice. It was found that the topical application of maize GlcCERs reduced the formation of wrinkles and epidermal thickening, suggesting its potential application in protecting photo-ageing.

\section{Opportunities, Challenges, and Future Perspectives}

\section{Opportunities and Challenges}

After the introduction of a relatively new field of research, sphingolipidomics, recent studies have focused on the isolation and structural characterization of plant sphingolipids. The availability of powerful analytical tools for structural elucidation and the enormous number of potential plants containing sphingolipids will increase the applications of phytoCERs in skin health improvement. The topical skin delivery of phytoCERs is one of the interesting areas of research for future studies.

Despite the fact that sphingolipids are ubiquitous in eukaryotes including plants, they are found in smaller amounts compared to other plant lipids. The total amounts of sphingolipids in plants also vary substantially. As a result, purification and enrichment of plant extracts are required prior to incorporating them into the various dietary and cosmetic formulations.

One of the major challenges in qualitative and quantitative analyses of GlcCERs is the limited commercial sources of authentic standards. The ideal standard for analysis is a compound with an identical structure/chemistry to the target plant-derived CERs. The synthetic version of CER standards are good alternatives for quantitative analysis of CERs in plants and pharmaceutical dosage forms. However, the commercially available synthetic standards have a different number/position of desaturation and hydroxylation on the SBs and FAs compared to the natural standards. For instance, commercially available CER standards
132

Skin Pharmacol Physiol 2017;30:115-138 DOI: $10.1159 / 000464337$
Tessema/Gebre-Mariam/Neubert/ Wohlrab 
usually have 4-sphingenine (d18:1 $\left.1^{\Delta 4}\right)$ SB. The plant SBs typically contain 4,8 -sphingadienine $\left(\mathrm{d} 18: 2^{\triangle 4,8}\right)$ and 4-hydroxy-8-sphingenine $\left(\mathrm{t} 18: 1^{\Delta 8}\right)$ SBs $[68,71]$. Calibration curves generated for the synthetic standards can be used for quantitative estimation of phytoCERs as the difference in signal intensity is being measured. However, in LC-MS analysis, minor structural variations in the SBs could affect the MS signal intensity. This is mainly attributed to the fact that the dehydration/deglucosylation of GlcCERs depends on the nature of C-4 of the SBs (GlcCERs containing C4hydroxylated/desaturated SBs are readily deglucosylated/ dehydrated) $[79,80]$. One can also consider synthesizing plant-identical GlcCERs and CERs to avoid the variability of signal intensity associated with structural variations. However, the existence of $\alpha$-hydroxy FAs and SBs desaturated at position 8 in phytoCERs makes the synthetic procedure laborious and expensive.

For plant GlcCERs meant for SC delivery, cleavage of the sugar moiety is inevitable. Different researchers have used the conventional acid/alkaline hydrolysis method for qualitative analysis of plant GlcCERs. However, these methods are not efficient for preparative purposes for a number of practical reasons. As GlcCERs are moderately resistant to acid hydrolysis, vigorous acid conditions are required. However, these drastic acidic conditions might result in different chemical alterations, racemization, and allylic rearrangements (formation of 3-O-methyl and 5-O-methyl ethers caused by the reaction of the allylic alcohol group with methanol in methanolic acids and the formation of 5-hydroxy isomers and dienic compounds in aqueous systems) [176-181]. As some of the derivatives are closely related, they have similar chromatographic properties, making the purification of the target CERs more difficult. The other more selective and efficient approach of transforming GlcCERs to CERs is enzymatic hydrolysis. There are few reports indicating the use of this method for the production of CERs. $\beta$-Glucosidase isolated from ox brain and $\beta$-galactosidase from rat brain were used to hydrolyze CER glucoside and CER lactoside, respectively $[182,183]$. Therefore, an effective and practically applicable method producing a good yield without stereo-inversion and fewer degradation by-products would be valuable for industrial applications.

\section{Conclusions and Future Perspectives}

Several studies conducted in vitro as well as in animal and human subjects showed the positive effects of orally administered plant-derived CERs on the skin barrier.
Based on the various reports, it is unlikely that dietary GlcCERs and/or SBs have direct effects as major constituents of SC lipid lamellae. On the other hand, several researchers have also suggested the possible mechanisms for skin barrier improvement, and most of the findings support the hypothesis that GlcCER metabolites are involved in barrier improvement. Whether the orally administered CERs are directly localized in the SC and stabilize the nanostructure of the skin or indirectly increase the in vivo production of skin CERs is still unclear, suggesting the need for more studies to elucidate and completely understand the mechanisms underlying barrier function improvement.

Although an effective amount of CERs can be topically delivered into the SC, compared to oral dietary supplements, limited published data are available on the topical administration of phytoCERs. More studies are needed to provide supporting evidence for the skin health benefits of phytoCERs. Also, the skin penetration of phytoCERs and their molecular arrangement in the SC nanostructure are still to be investigated. This will give an insight into the influence of structural variations of phytoCERs on the morphology of the lipid structure and the possibility of mimicking the structure and function of the natural skin barrier. As phytoCERs exist mainly in glycosylated form, the possibility of delivering CER precursors like GlcCERs into the viable layers of the epidermis as a way of correcting the reduced CER level in the SC would be an alternative strategy. For CERs meant for SC delivery, an effective method of hydrolysis, either chemical or enzymatic, has to be developed and optimized to investigate the effect of free CERs on skin barrier improvement.

\section{Acknowledgement}

Efrem N. Tessema greatly acknowledges the financial support provided by the German Academic Exchange Service (DAAD).

\section{Disclosure Statement}

The authors declare no conflict of interest.

Phyto-Derived Ceramides 


\section{References}

1 Proksch E, Brandner JM, Jensen JM: The skin: an indispensable barrier. Exp Dermatol 2008; 17:1063-1072.

2 van Smeden J, Janssens M, Gooris GS, Bouwstra JA: The important role of stratum corneum lipids for the cutaneous barrier function. Biochim Biophys Acta 2014;1841:295313.

3 Holleran WM, Takagi Y, Uchida Y: Epidermal sphingolipids: metabolism, function, and roles in skin disorders. FEBS Lett 2006;580: 5456-5466.

4 Menon GK, Cleary GW, Lane ME: The structure and function of the stratum corneum. Int J Pharm 2012;435:3-9.

5 Wartewig S, Neubert RH: Properties of ceramides and their impact on the stratum corneum structure: a review. Part 1. Ceramides. Skin Pharmacol Physiol 2007;20:220-229.

6 Imokawa G, Abe A, Jin K, Higaki Y, Kawashima M, Hidano A: Decreased level of ceramides in stratum-corneum of atopic-dermatitis - an etiologic factor in atopic dry skin. J Invest Dermatol 1991;96:523-526.

7 Di Nardo A, Wertz P, Giannetti A, Seidenari S: Ceramide and cholesterol composition of the skin of patients with atopic dermatitis. Acta Derm Venereol 1998;78:27-30.

8 Motta S, Monti M, Sesana S, Caputo R, Carelli S, Ghidoni R: Ceramide composition of the psoriatic scale. Biochim Biophys Acta 1993; 1182:147-151.

9 Motta S, Monti M, Sesana S, Mellesi L, Ghidoni R, Caputo R: Abnormality of water barrier function in psoriasis - role of ceramide fractions. Arch Dermatol 1994;130:452-456.

10 Rogers J, Harding C, Mayo A, Banks J, Rawlings A: Stratum corneum lipids: the effect of ageing and the seasons. Arch Dermatol Res 1996;288:765-770.

11 Sahle FF, Gebre-Mariam T, Dobner B, Wohlrab J, Neubert RH: Skin diseases associated with the depletion of stratum corneum lipids and stratum corneum lipid substitution therapy. Skin Pharmacol Phys 2015;28:42-55.

12 Ono J, Kinoshita M, Aida K, Tamura M, Ohnishi M: Effects of dietary glucosylceramide on dermatitis in atopic dermatitis model mice. Eur J Lipid Sci Tech 2010;112:708-711.

13 Adam D: Review blames BSE outbreak on calf feed. Nature 2001;412:467.

14 Uchiyama T, Nakano Y, Ueda O, Mori H, Nakashima M, Noda A, Ishizaki C, Mizoguchi $\mathrm{M}$ : Oral intake of glucosylceramide improves relatively higher level of transepidermal water loss in mice and healthy human subjects. J Health Sci 2008;54:559-566.

15 Tsuji K, Mitsutake S, Ishikawa J, Takagi Y, Akiyama $\mathrm{M}$, Shimizu $\mathrm{H}$, Tomiyama T, Igarashi Y: Dietary glucosylceramide improves skin barrier function in hairless mice. J Dermatol Sci 2006;44:101-107.

16 Shimoda H, Terazawa S, Hitoe S, Tanaka J, Nakamura S, Matsuda H, Yoshikawa M Changes in ceramides and glucosylceramides in mouse skin and human epidermal equivalents by rice-derived glucosylceramide. J Med Food 2012;15:1064-1072.

17 Kuempel D, Swartzendruber DC, Squier CA, Wertz PW: In vitro reconstitution of stratum corneum lipid lamellae. Biochim Biophys Acta 1998;1372:135-140.

18 Bouwstra JA, Honeywell-Nguyen PL: Skin structure and mode of action of vesicles. Adv Drug Deliv Rev 2002;54(suppl 1):S41-S55.

19 Bouwstra JA, Ponec M: The skin barrier in healthy and diseased state. Biochim Biophys Acta 2006;1758:2080-2095.

20 Man MM, Feingold KR, Thornfeldt CR, Elias PM: Optimization of physiological lipid mixtures for barrier repair. J Invest Dermatol 1996;106:1096-1101.

21 Mizutani Y, Mitsutake S, Tsuji K, Kihara A, Igarashi Y: Ceramide biosynthesis in keratinocyte and its role in skin function. Biochimie 2009;91:784-790.

22 Ponec M, Weerheim A, Lankhorst P, Wertz P: New acylceramide in native and reconstructed epidermis. J Invest Dermatol 2003;120: 581-588.

23 Masukawa Y, Narita H, Shimizu E, Kondo N, Sugai Y, Oba T, Homma R, Ishikawa J, Takagi Y, Kitahara T, Takema Y, Kita K: Characterization of overall ceramide species in human stratum corneum. J Lipid Res 2008;49: 1466-1476.

24 Masukawa Y, Narita H, Sato H, Naoe A, Kondo N, Sugai Y, Oba T, Homma R, Ishikawa J, Takagi Y, Kitahara T: Comprehensive quantification of ceramide species in human stratum corneum. J Lipid Res 2009;50:17081719.

25 Kessner D, Kiselev M, Dante S, Hauss T, Lersch P, Wartewig S, Neubert RH: Arrangement of ceramide (EOS) in a stratum corneum lipid model matrix: new aspects revealed by neutron diffraction studies. Eur Biophys J 2008;37:989-999.

26 Schroter A, Kessner D, Kiselev MA, Hauss T, Dante S, Neubert RH: Basic nanostructure of stratum corneum lipid matrices based on ceramides (EOS) and (AP): a neutron diffraction study. Biophys J 2009;97: 1104-1114.

27 Wartewig S, Neubert RH: Properties of ceramides and their impact on the stratum corneum structure: a review. Skin Pharmacol Phys 2007;20:220-229.

28 de Sousa Neto D, Gooris G, Bouwstra J: Effect of the $\omega$-acylceramides on the lipid organization of stratum corneum model membranes evaluated by X-ray diffraction and FTIR studies (Part I). Chem Phys Lipids 2011;164:184195.

29 Behne M, Uchida Y, Seki T, de Montellano PO, Elias PM, Holleran WM: Omega-hydroxyceramides are required for corneocyte lipid envelope (CLE) formation and normal epidermal permeability barrier function. J Invest Dermatol 2000;114:185-192.
30 Uchida Y, Holleran WM: Omega-o-acylceramide, a lipid essential for mammalian survival. J Dermatol Sci 2008;51:77-87.

31 t'Kindt R, Jorge L, Dumont E, Couturon P, David F, Sandra P, Sandra K: Profiling and characterizing skin ceramides using reversedphase liquid chromatography-quadrupole time-of-flight mass spectrometry. Anal Chem 2012;84:403-411.

32 Robson KJ, Stewart ME, Michelsen S, Lazo ND, Downing DT: 6-hydroxy-4-sphingenine in human epidermal ceramides. J Lipid Res 1994;35:2060-2068.

33 Farwanah H, Wohlrab J, Neubert RH, Raith $\mathrm{K}$ : Profiling of human stratum corneum ceramides by means of normal phase LC/APCIMS. Anal Bioanal Chem 2005;383:632-637.

34 Farwanah H, Raith K, Neubert RH, Wohlrab $\mathrm{J}$ : Ceramide profiles of the uninvolved skin in atopic dermatitis and psoriasis are comparable to those of healthy skin. Arch Dermatol Res 2005;296:514-521.

35 Uchida Y, Holleran WM, Elias PM: On the effects of topical synthetic pseudoceramides: comparison of possible keratinocyte toxicities provoked by the pseudoceramides, PC104 and BIO391, and natural ceramides. J Dermatol Sci 2008;51:37-43.

36 Carneiro R, Salgado A, Raposo S, Marto J, Simoes S, Urbano M, Ribeiro HM: Topical emulsions containing ceramides: effects on the skin barrier function and anti-inflammatory properties. Eur J Lipid Sci Tech 2011;113:961-966.

37 Moore DJ, Rerek ME: Insights into the molecular organization of lipids in the skin barrier from infrared spectroscopy studies of stratum corneum lipid models. Acta Derm Venereol 2000;16-22.

38 Hamanaka S, Nakazawa S, Yamanaka M, Uchida Y, Otsuka F: Glucosylceramide accumulates preferentially in lamellar bodies in differentiated keratinocytes. Br J Dermatol 2005; 152:426-434.

39 Hamanaka S, Hara M, Nishio H, Otsuka F, Suzuki A, Uchida Y: Human epidermal glucosylceramides are major precursors of stratum corneum ceramides. J Invest Dermatol 2002; 119:416-423.

40 Alessandrini F, Pfister S, Kremmer E, Gerber JK, Ring J, Behrendt H: Alterations of glucosylceramide-beta-glucosidase levels in the skin of patients with psoriasis vulgaris. J Invest Dermatol 2004;123:1030-1036.

41 Vielhaber G, Pfeiffer S, Brade L, Lindner B, Goldmann T, Vollmer E, Hintze U, Wittern KP, Wepf R: Localization of ceramide and glucosylceramide in human epidermis by immunogold electron microscopy. J Invest Dermatol 2001;117:1126-1136.

42 Uchida Y, Hara M, Nishio H, Sidransky E, Inoue S, Otsuka F, Suzuki A, Elias PM, Holleran WM, Hamanaka S: Epidermal sphingomyelins are precursors for selected stratum corneum ceramides. J Lipid Res 2000;41:20712082. 
43 Holleran WM, Ginns EI, Menon GK, Grundmann JU, Fartasch M, McKinney CE, Elias PM, Sidransky E: Consequences of beta-glucocerebrosidase deficiency in epidermis. Ultrastructure and permeability barrier alterations in Gaucher disease. J Clin Invest 1994; 93:1756-1764.

44 Holleran WM, Takagi Y, Uchida Y: Epidermal sphingolipids: metabolism, function, and roles in skin disorders. FEBS Lett 2006;580: 5456-5466.

45 Grayson S, Elias PM: Isolation and lipid biochemical characterization of stratum corneum membrane complexes: implications for the cutaneous permeability barrier. J Invest Dermatol 1982;78:128-135.

46 Breathnach AS, Goodman T, Stolinski C, Gross M: Freeze-fracture replication of cells of stratum corneum of human epidermis. J Anat 1973;114:65-81.

47 Breathnach AS: Aspects of epidermal ultrastructure. J Invest Dermatol 1975;65:2-15.

48 Madison KC, Swartzendruber DC, Wertz PW, Downing DT: Presence of intact intercellular lipid lamellae in the upper layers of the stratum corneum. J Invest Dermatol 1987;88: 714-718.

49 Hou SY, Mitra AK, White SH, Menon GK, Ghadially R, Elias PM: Membrane structures in normal and essential fatty acid-deficient stratum corneum: characterization by ruthenium tetroxide staining and $\mathrm{x}$-ray diffraction. J Invest Dermatol 1991;96:215-223.

50 Bouwstra JA, Gooris GS, van der Spek JA, Bras W: Structural investigations of human stratum corneum by small-angle X-ray scattering. J Invest Dermatol 1991;97:1005-1012.

51 Bouwstra JA, Gooris GS, Dubbelaar FE, Weerheim AM, Ijzerman AP, Ponec M: Role of ceramide 1 in the molecular organization of the stratum corneum lipids. J Lipid Res 1998;39:186-196.

52 McIntosh TJ, Stewart ME, Downing DT: Xray diffraction analysis of isolated skin lipids: reconstitution of intercellular lipid domains. Biochemistry 1996;35:3649-3653.

53 de Jager MW, Gooris GS, Ponec M, Bouwstra JA: Lipid mixtures prepared with well-defined synthetic ceramides closely mimic the unique stratum corneum lipid phase behavior. J Lipid Res 2005;46:2649-2656.

54 Kiselev MA, Ryabova NY, Balagurov AM, Dante S, Hauss T, Zbytovska J, Wartewig S, Neubert RH: New insights into the structure and hydration of a stratum corneum lipid model membrane by neutron diffraction. Eur Biophys J 2005;34:1030-1040.

55 Engelbrecht TN, Schroeter A, Hauss T, Deme B, Scheidt HA, Huster D, Neubert RH: The impact of ceramides NP and AP on the nanostructure of stratum corneum lipid bilayer. Part I. Neutron diffraction and ${ }^{2} \mathrm{H}$ NMR studies on multilamellar models based on ceramides with symmetric alkyl chain length distribution. Soft Matter 2012;8:6599-6607.

56 Kessner D, Ruettinger A, Kiselev MA, Wartewig S, Neubert RH: Properties of ceramides and their impact on the stratum corneum structure. Part 2. Stratum corneum lipid model systems. Skin Pharmacol Physiol 2008; 21:58-74.

57 Bleck O, Abeck D, Ring J, Hoppe U, Vietzke JP, Wolber R, Brandt O, Schreiner V: Two ceramide subfractions detectable in Cer(AS) position by HPTLC in skin surface lipids of non-lesional skin of atopic eczema. J Invest Dermatol 1999;113:894-900.

58 Macheleidt O, Kaiser HW, Sandhoff K: Deficiency of epidermal protein-bound omegahydroxyceramides in atopic dermatitis. J Invest Dermatol 2002;119:166-173.

59 Hara J, Higuchi K, Okamoto R, Kawashima M, Imokawa G: High expression of sphingomyelin deacylase is an important determinant of ceramide deficiency leading to barrier disruption in atopic dermatitis. J Invest Dermatol 2000;115:406-413.

60 Imokawa G: A possible mechanism underlying the ceramide deficiency in atopic dermatitis: expression of a deacylase enzyme that cleaves the $\mathrm{N}$-acyl linkage of sphingomyelin and glucosylceramide. J Dermatol Sci 2009; 55:1-9.

61 Ishibashi M, Arikawa J, Okamoto R, Kawashima M, Takagi Y, Ohguchi K, Imokawa G: Abnormal expression of the novel epidermal enzyme, glucosylceramide deacylase, and the accumulation of its enzymatic reaction product, glucosylsphingosine, in the skin of patients with atopic dermatitis. Lab Invest 2003;83: 397-408.

62 Ohnishi Y, Okino N, Ito M, Imayama S: Ceramidase activity in bacterial skin flora as a possible cause of ceramide deficiency in atopic dermatitis. Clin Diagn Lab Immun 1999;6: 101-104.

63 Jin K, Higaki Y, Takagi Y, Higuchi K, Yada Y, Kawashima M, Imokawa G: Analysis of betaglucocerebrosidase and ceramidase activities in atopic and aged dry skin. Acta Derm Venereol 1994;74:337-340.

64 Kusuda S, Cui CY, Takahashi M, Tezuka T: Localization of sphingomyelinase in lesional skin of atopic dermatitis patients. J Invest Dermatol 1998;111:733-738.

65 Berardesca E, Fideli D, Borroni G, Rabbiosi G, Maibach $\mathrm{H}$ : In vivo hydration and water-retention capacity of stratum corneum in clinically uninvolved skin in atopic and psoriatic patients. Acta Derm Venereol 1990;70:400404.

66 Serup J, Blichmann C: Epidermal hydration of psoriasis plaques and the relation to scaling - measurement of electrical conductance and trans-epidermal water loss. Acta Derm Venereol 1987;67:357-359.

67 Alessandrini F, Stachowitz S, Ring J, Behrendt $\mathrm{H}$ : The level of prosaposin is decreased in the skin of patients with psoriasis vulgaris. J Invest Dermatol 2001;116:394-400.

68 Sperling P, Heinz E: Plant sphingolipids: structural diversity, biosynthesis, first genes and functions. Biochim Biophys Acta 2003; 1632:1-15.
69 Spassieva S, Hille J: Plant sphingolipids today - are they still enigmatic? Plant Biol 2003;5: 125-136.

70 Pata MO, Hannun YA, Ng CKY: Plant sphingolipids: decoding the enigma of the sphinx. New Phytol 2010;185:611-630.

71 Lynch DV, Dunn TM: An introduction to plant sphingolipids and a review of recent advances in understanding their metabolism and function. New Phytol 2004;161:677-702.

72 Warnecke D, Heinz E: Recently discovered functions of glucosylceramides in plants and fungi. Cell Mol Life Sci 2003;60:919-941.

73 Fujino Y, Ohnishi M, Ito S: Molecular-species of ceramide and mono-glycosylceramide, diglycosylceramide, tri-glycosylceramide, and tetraglycosylceramide in bran and endosperm of rice grains. Agric Biol Chem Tokyo 1985; 49:2753-2762.

74 Ohnishi M, Ito S, Fujino Y: Sphingolipid classes and their molecular species in wheatflour. Agric Biol Chem Tokyo 1985;49:36093611.

75 Bromley PE, Li YO, Murphy SM, Sumner CM, Lynch DV: Complex sphingolipid synthesis in plants: characterization of inositolphosphorylceramide synthase activity in bean microsomes. Arch Biochem Biophys 2003; 417:219-226.

76 Markham JE, Lynch DV, Napier JA, Dunn TM, Cahoon EB: Plant sphingolipids: function follows form. Curr Opin Plant Biol 2013; 16:350-357.

77 Sullards MC, Lynch DV, Merrill AH Jr, Adams J: Structure determination of soybean and wheat glucosylceramides by tandem mass spectrometry. J Mass Spectr 2000;35:347-353.

78 Sperling P, Libisch B, Zahringer U, Napier JA, Heinz E: Functional identification of a $\Delta^{8}$ sphingolipid desaturase from Borago officinalis. Arch Biochem Biophys 2001;388:293-298.

79 Sugawara T, Duan J, Aida K, Tsuduki T, Hirata $\mathrm{T}$ : Identification of glucosylceramides containing sphingatrienine in maize and rice using ion trap mass spectrometry. Lipids 2010;45:451-455.

80 Sugawara T, Aida K, Duan J, Hirata T: Analysis of glucosylceramides from various sources by liquid chromatography-ion trap mass spectrometry. J Oleo Sci 2010;59:387-394.

81 Breiden B, Sandhoff K: The role of sphingolipid metabolism in cutaneous permeability barrier formation. Biochim Biophys Acta 2014;1841:441-452.

82 Imai H, Ohnishi M, Hotsubo K, Kojima M, Ito S: Sphingoid base composition of cerebrosides from plant leaves. Biosci Biotech Biochem 1997;61:351-353.

83 Ohnishi M, Ito S, Fujino Y: Characterization of sphingolipids in spinach leaves. Biochim Biophys Acta 1983;752:416-422.

84 Fujino Y, Ohnishi M: Sphingolipids in wheatgrain. J Cereal Sci 1983;1:159-168.

85 Imai H, Morimoto Y, Tamura K: Sphingoid base composition of monoglucosylceramide in Brassicaceae. J Plant Physiol 2000;157:453456. 
86 Imai H, Ohnishi M, Kinoshita M, Kojima M, Ito S: Structure and distribution of cerebroside containing unsaturated hydroxy fattyacids in plant-leaves. Biosci Biotech Biochem 1995;59:1309-1313.

87 Imai H, Yamamoto K, Shibahara A, Miyatani S, Nakayama T: Determining double-bond positions in monoenoic 2-hydroxy fatty acids of glucosylceramides by gas chromatographymass spectrometry. Lipids 2000;35:233-236.

88 Uemura M, Steponkus PL: A contrast of the plasma-membrane lipid-composition of oat and rye leaves in relation to freezing tolerance. Plant Physiol 1994;104:479-496.

89 Ohnishi M, Fujino Y: Sphingolipids in immature and mature soybeans. Lipids 1982;17: 803-810.

90 Cahoon EB, Lynch DV: Analysis of glucocerebrosides of rye (Secale cereale L cv Puma) leaf and plasma membrane. Plant Physiol 1991; 95:58-68.

91 Napolitano A, Benavides A, Pizza C, Piacente S: Qualitative on-line profiling of ceramides and cerebrosides by high performance liquid chromatography coupled with electrospray ionization ion trap tandem mass spectrometry: the case of Dracontium loretense. J Pharm Biomed Anal 2011;55:23-30.

92 Markham JE, Li J, Cahoon EB, Jaworski JG: Separation and identification of major plant sphingolipid classes from leaves. J Biol Chem 2006;281:22684-22694.

93 Farwanah H, Kolter T, Sandhoff K: Mass spectrometric analysis of neutral sphingolipids: methods, applications, and limitations. Biochim Biophys Acta 2011;1811:854-860.

94 Markham JE, Jaworski JG: Rapid measurement of sphingolipids from Arabidopsis thaliana by reversed-phase high-performance liquid chromatography coupled to electrospray ionization tandem mass spectrometry. Rapid Commun Mass Spectrom 2007;21:1304-1314.

95 Pettus BJ, Bielawska A, Kroesen BJ, Moeller PDR, Szulc ZM, Hannun YA, Busman M: Observation of different ceramide species from crude cellular extracts by normal-phase highperformance liquid chromatography coupled to atmospheric pressure chemical ionization mass spectrometry. Rapid Commun Mass Spectrom 2003;17:1203-1211.

96 Bartke N, Fischbeck A, Humpf HU: Analysis of sphingolipids in potatoes (Solanum tuberosum L.) and sweet potatoes (Ipomoea batatas (L.) lam.) by reversed phase high-performance liquid chromatography electrospray ionization tandem mass spectrometry (HPLC-ESI-MS/MS). Mol Nutr Food Res 2006;50:1201-1211.

97 Farwanah H, Wirtz J, Kolter T, Raith K, Neubert RH, Sandhoff K: Normal phase liquid chromatography coupled to quadrupole time of flight atmospheric pressure chemical ionization mass spectrometry for separation, detection and mass spectrometric profiling of neutral sphingolipids and cholesterol. J Chromatogr B Analyt Technol Biomed Life Sci 2009;877:2976-2982.
98 Tokudome Y, Endo M, Hashimoto F: Application of glucosylceramide-based liposomes increased the ceramide content in a three-dimensional cultured skin epidermis. Skin Pharmacol Physiol 2014;27:18-24.

99 Ueda O, Hasegawa M, Kitamura S: Distribution in skin of ceramide after oral administration to rats. Drug Metab Pharmacokinet 2009;24:180-184.

100 Fujino Y, Ohnishi M: Species of sphingolipids in rice grain. Proc Jpn Acad Ser B Phys Biol Sci 1982;58:36-39.

101 Aida K, Kinoshita M, Tanji M, Sugawara T, Tamura M, Ono J, Ueno N, Ohnishi M: Prevention of aberrant crypt foci formation by dietary maize and yeast cerebrosides in 1,2-dimethylhydrazine-treated mice. J Oleo Sci 2005;54:45-49.

102 Gutierrez E, Wang T, Fehr WR: Quantification of sphingolipids in soybeans. J Am Oil Chem Soc 2004;81:737-742.

103 Shirakura Y, Kikuchi K, Matsumura K, Mukai K, Mitsutake S, Igarashi Y: 4,8-sphingadienine and 4-hydroxy-8-sphingenine activate ceramide production in the skin. Lipids Health Dis 2012;11:108.

104 Usuki S, Tamura N, Sakai S, Tamura T, Mukai K, Igarashi Y: Chemoenzymatically prepared konjac ceramide inhibits NGF-induced neurite outgrowth by a semaphorin 3A-like action. Biochem Biophys Rep 2016; 5:160-167.

105 Fujino Y, Ohnishi M: Constituents of ceramide and ceramide monohexoside in rice bran. Chem Phys Lipids 1976;17:275-289.

106 Kimata H: Improvement of atopic dermatitis and reduction of skin allergic responses by oral intake of konjac ceramide. Pediatr Dermatol 2006;23:386-389.

107 Goto H, Nishikawa K, Shionoya N, Taniguchi M, Igarashi T: Determination of sphingoid bases from hydrolyzed glucosylceramide in rice and wheat by online post-column high-performance liquid chromatography with $\mathrm{O}$-phthalaldehyde derivatization. J Oleo Sci 2012;61:681-688.

108 Sugawara T, Kinoshita M, Ohnishi M, Nagata J, Saito M: Digestion of maize sphingolipids in rats and uptake of sphingadienine by Caco-2 cells. J Nutr 2003;133:2777-2782.

109 Guillou S, Ghabri S, Jannot C, Gaillard E, Lamour I, Boisnic S: The moisturizing effect of a wheat extract food supplement on women's skin: a randomized, double-blind placebo-controlled trial. Int J Cosmet Sci 2011;33: 138-143.

110 Yeom M, Kim SH, Lee B, Han JJ, Chung GH, Choi HD, Lee H, Hahm DH: Oral administration of glucosylceramide ameliorates inflammatory dry-skin condition in chronic oxazolone-induced irritant contact dermatitis in the mouse ear. J Dermatol Sci 2012;67: 101-110.

111 Kawano K, Umemura K: Oral intake of beet extract provides protection against skin barrier impairment in hairless mice. Phytother Res 2013;27:775-783.
112 Miyanishi K, Shiono N, Shirai H, Dombo M, Kimata H: Reduction of transepidermal water loss by oral intake of glucosylceramides in patients with atopic eczema. Allergy 2005; 60:1454-1455.

113 Loden M, Barany E: Skin-identical lipids versus petrolatum in the treatment of tapestripped and detergent-perturbed human skin. Acta Derm Venereol 2000;80:412415.

114 Fujii M, Tomozawa J, Mizutani N, Nabe T, Danno K, Kohno S: Atopic dermatitis-like pruritic skin inflammation caused by feeding a special diet to HR-1 hairless mice. Exp Dermatol 2005;14:460-468.

115 Makiura M, Akamatsu H, Akita H, Yagami A, Shimizu Y, Eiro H, Kuramoto M, Suzuki $\mathrm{K}$, Matsunaga $\mathrm{K}$ : Atopic dermatitis-like symptoms in HR-1 hairless mice fed a diet low in magnesium and zinc. J Int Med Res 2004;32:392-399.

116 Kang JS, Youm JK, Jeong SK, Park BD, Yoon WK, Han MH, Lee H, Han SB, Lee K, Park SK, Lee SH, Yang KH, Moon EY, Kim HM: Topical application of a novel ceramide derivative, K6PC-9, inhibits dust mite extractinduced atopic dermatitis-like skin lesions in $\mathrm{NC} / \mathrm{Nga}$ mice. Int Immunopharmacol 2007;7:1589-1597.

117 Hori M, Kishimoto S, Tezuka Y, Nishigori H, Nomoto K, Hamada U, Yonei Y: Doubleblind study on effects of glucosyl ceramide in beet extract on skin elasticity and fibronectin production in human dermal fibroblasts. Anti Aging Med 2010;7:129-142.

118 Nilsson A: The presence of sphingomyelinand ceramide-cleaving enzymes in the small intestinal tract. Biochim Biophys Acta 1969; 176:339-347.

119 Nilsson A: Metabolism of sphingomyelin in the intestinal tract of the rat. Biochim Biophys Acta 1968; 164:575-584.

120 Nilsson A: Metabolism of cerebroside in the intestinal tract of the rat. Biochim Biophys Acta 1969;187:113-121.

121 Schmelz EM, Crall KJ, Larocque R, Dillehay DL, Merrill AH Jr: Uptake and metabolism of sphingolipids in isolated intestinal loops of mice. J Nutr 1994;124:702-712.

122 Nyberg L, Nilsson A, Lundgren P, Duan RD: Localization and capacity of sphingomyelin digestion in the rat intestinal tract. J Nutr Biochem 1997;8:112-118.

123 Leese HJ, Semenza G: On the identity between the small intestinal enzymes phlorizin hydrolase and glycosylceramidase. J Biol Chem 1973;248:8170-8173.

124 Buller HA, Van Wassenaer AG, Raghavan S, Montgomery RK, Sybicki MA, Grand RJ: New insights into lactase and glycosylceramidase activities of rat lactase-phlorizin hydrolase. Am J Physiol 1989;257:G616G623.

125 Duan RD, Cheng Y, Yang L, Ohlsson L, Nilsson A: Evidence for specific ceramidase present in the intestinal contents of rats and humans. Lipids 2001;36:807-812. 
126 Olsson M, Duan RD, Ohlsson L, Nilsson A: Rat intestinal ceramidase: purification, properties, and physiological relevance. Am J Physiol Gastrointest Liver Physiol 2004; 287:G929-G937.

127 Kono M, Dreier JL, Ellis JM, Allende ML, Kalkofen DN, Sanders KM, Bielawski J, Bielawska A, Hannun YA, Proia RL: Neutral ceramidase encoded by the Asah2 gene is essential for the intestinal degradation of sphingolipids. J Biol Chem 2006;281:73247331.

128 Nilsson A, Duan RD: Absorption and lipoprotein transport of sphingomyelin. J Lipid Res 2006;47:154-171.

129 Sugawara T, Kinoshita M, Ohnishi M, Tsuzuki T, Miyazawa T, Nagata J, Hirata T, Saito M: Efflux of sphingoid bases by P-glycoprotein in human intestinal Caco-2 cells. Biosci Biotech Biochem 2004;68:2541-2546.

130 Renkonen O, Hirvisal EL: Structure of plasma sphingadienine. J Lipid Res 1969;10: 687-693.

131 Ando S, Isobe M, Nagai Y: High-performance preparative column chromatography of lipids using a new porous silica, Iatrobeads.1. Separation of molecular species of sphingoglycolipids. Biochim Biophys Acta 1976;424:98-105.

132 Colsch B, Afonso C, Popa L, Portoukalian J, Fournier F, Tabet JC, Baumann N: Characterization of the ceramide moieties of sphingoglycolipids from mouse brain by ESI-MS/ MS: identification of ceramides containing sphingadienine. J Lipid Res 2004;45:281286.

133 Ishikawa J, Takada S, Hashizume K, Takagi Y, Hotta M, Masukawa Y, Mizutani Y, Igarashi Y: Dietary glucosylceramide is absorbed into the lymph and increases levels of epidermal sphingolipids. J Dermatol Sci 2009;56:216-218.

134 Sugawara T, Tsuduki T, Yano S, Hirose M, Duan JJ, Aida K, Ikeda I, Hirata T: Intestinal absorption of dietary maize glucosylceramide in lymphatic duct cannulated rats. J Lipid Res 2010;51:1761-1769.

135 Takeda S, Mitsutake S, Tsuji K, Igarashi Y: Apoptosis occurs via the ceramide recycling pathway in human $\mathrm{HaCaT}$ keratinocytes. J Biochem 2006;139:255-262.

136 Ueda O, Uchiyama T, Nakashima M: Distribution and metabolism of sphingosine in skin after oral administration to mice. Drug Metab Pharmacokinet 2010;25:456-465.

137 Duan JJ, Sugawara T, Hirose M, Aida K, Sakai S, Fujii A, Hirata T: Dietary sphingolipids improve skin barrier functions via the upregulation of ceramide synthases in the epidermis. Exp Dermatol 2012;21:448452.

138 Hitomi K: Transglutaminases in skin epidermis. Eur J Dermatol 2005;15:313-319.

139 Kunii T, Hirao T, Kikuchi K, Tagami H: Stratum corneum lipid profile and maturation pattern of corneocytes in the outermost layer of fresh scars: the presence of imma- ture corneocytes plays a much more important role in the barrier dysfunction than do changes in intercellular lipids. Br J Dermatol 2003;149:749-756.

140 Kirschner N, Bohner C, Rachow S, Brandner JM: Tight junctions: is there a role in dermatology? Arch Dermatol Res 2010;302:483493.

141 Ideta R, Sakuta T, Nakano Y, Uchiyama T: Orally administered glucosylceramide improves the skin barrier function by upregulating genes associated with the tight junction and cornified envelope formation. Biosci Biotechnol Biochem 2011;75:15161523.

142 Hasegawa T, Shimada H, Uchiyama T, Ueda O, Nakashima M, Matsuoka Y: Dietary glucosylceramide enhances cornified envelope formation via transglutaminase expression and involucrin production. Lipids 2011;46: 529-535.

143 Kawada C, Hasegawa T, Watanabe M, Nomura Y: Dietary glucosylceramide enhances tight junction function in skin epidermis via induction of claudin-1. Biosci Biotechnol Biochem 2013;77:867-869.

144 Murakami I, Wakasa Y, Yamashita S, Kurihara T, Zama K, Kobayashi N, Mizutani Y, Mitsutake S, Shigyo T, Igarashi Y: Phytoceramide and sphingoid bases derived from brewer's yeast Saccharomyces pastorianus activate peroxisome proliferator-activated receptors. Lipids Health Dis 2011;10:150.

145 Takatori R, Le Vu P, Iwamoto T, Satsu H, Totsuka M, Chida K, Shimizu M: Effects of oral administration of glucosylceramide on gene expression changes in hairless mouse skin: comparison of whole skin, epidermis, and dermis. Biosci Biotechnol Biochem 2013;77:1882-1887.

146 Lin J-Y, Selim MA, Shea CR, Grichnik JM, Omar MM, Monteiro-Riviere NA, Pinnell SR: UV photoprotection by combination topical antioxidants vitamin $\mathrm{C}$ and vitamin E. J Am Acad Dermatol 2003;48:866-874.

147 Gasperlin M, Gosenca M: Main approaches for delivering antioxidant vitamins through the skin to prevent skin ageing. Exp Opin Drug Deliv 2011;8:905-919.

148 Clinical investigation of skin-beautifying effect of a beauty supplement containing ricederived ceramide. Ichinomiya, Oryza Oil \& Fat Chemical Co. Ltd., 2000.

149 Deschamps FS, Gaudin K, Baillet A, Chaminade P: Wheat digalactosyldiacylglycerol molecular species profiling using porous graphitic carbon stationary phase. J Sep Sci 2004;27:1313-1322.

150 Sugawara T, Miyazawa T: Beneficial effect of dietary wheat glycolipids on cecum shortchain fatty acid and secondary bile acid profiles in mice. J Nutr Sci Vitaminol (Tokyo) 2001;47:299-305.

151 Djedour A, Lafforgue C, Marty JP, Grossiord JL: A very promising new glucolipidic surfactant: Lipowheat. Int J Cosmet Sci 2005;27: 301-308.
152 SEPPIC: Ceramosides: Highly powerful source of phytoceramides from wheat. Paris, SEPPIC, 2016

153 Hon KL, Leung AK: Use of ceramides and related products for childhood-onset eczema. Recent Pat Inflamm Allergy Drug Discov 2013;7:12-19.

154 Grimalt R, Mengeaud V, Cambazard F; Study Investigators' Group: The steroid-sparing effect of an emollient therapy in infants with atopic dermatitis: a randomized controlled study. Dermatology 2007;214:61-67.

155 Loden M, Wiren K, Smerud K, Meland N, Honnas H, Mork G, Lutzow-Holm C, Funk J, Meding B: Treatment with a barrierstrengthening moisturizer prevents relapse of hand-eczema: an open, randomized, prospective, parallel group study. Acta Derm Venereol 2010;90:602-606.

156 Simpson EL: Atopic dermatitis: a review of topical treatment options. Curr Med Res Opin 2010;26:633-640.

157 Frankel A, Sohn A, Patel RV, Lebwohl M: Bilateral comparison study of pimecrolimus cream $1 \%$ and a ceramide-hyaluronic acid emollient foam in the treatment of patients with atopic dermatitis. J Drugs Dermatol 2011;10:666-672.

158 Chamlin SL, Kao J, Frieden IJ, Sheu MY, Fowler AJ, Fluhr JW, Williams ML, Elias PM: Ceramide-dominant barrier repair lipids alleviate childhood atopic dermatitis: changes in barrier function provide a sensitive indicator of disease activity. J Am Acad Dermatol 2002;47:198-208.

159 Weber TM, Kausch M, Rippke F, Schoelermann AM, Filbry AW: Treatment of xerosis with a topical formulation containing glyceryl glucoside, natural moisturizing factors, and ceramide. J Clin Aesthet Dermatol 2012; 5:29-39.

160 Hon KL, Wang SS, Lau Z, Lee HC, Lee KK, Leung TF, Luk NM: Pseudoceramide for childhood eczema: does it work? Hong Kong Med J 2011;17:132-136.

161 Lee YB, Park HJ, Kwon MJ, Jeong SK, Cho $\mathrm{SH}$ : Beneficial effects of pseudoceramidecontaining physiologic lipid mixture as a vehicle for topical steroids. Eur J Dermatol 2011;21:710-716.

162 Kim HJ, Park HJ, Yun JN, Jeong SK, Ahn SK, Lee SH: Pseudoceramide-containing physiological lipid mixture reduces adverse effects of topical steroids. Allergy Asthma Immunol Res 2011;3:96-102.

163 de Jager MW, Gooris GS, Dolbnya IP, Ponec $\mathrm{M}$, Bouwstra JA: Modelling the stratum corneum lipid organisation with synthetic lipid mixtures: the importance of synthetic ceramide composition. Biochim Biophys Acta 2004;1664:132-140.

164 Sahle FF, Wohlrab J, Neubert RH: Controlled penetration of ceramides into and across the stratum corneum using various types of microemulsions and formulation associated toxicity studies. Eur J Pharm Biopharm 2014;86:244-250. 
165 Loden M: The skin barrier and use of moisturizers in atopic dermatitis. Clin Dermatol 2003;21:145-157.

166 Coderch L, De Pera M, Fonollosa J, De la Maza A, Parra J: Efficacy of stratum corneum lipid supplementation on human skin. Contact Dermatitis 2002;47:139-146.

167 de Pera M, Coderch L, Fonollosa J, de la Maza A, Parra JL: Effect of internal wool lipid liposomes on skin repair. Skin Pharmacol Appl Skin Physiol 2000;13:188-195.

168 Heuschkel S, Goebel A, Neubert RH: Microemulsions - modern colloidal carrier for dermal and transdermal drug delivery. J Pharm Sci 2008;97:603-631.

169 Sahle FF, Metz H, Wohlrab J, Neubert RH: Polyglycerol fatty acid ester surfactantbased microemulsions for targeted delivery of ceramide AP into the stratum corneum: formulation, characterisation, in vitro release and penetration investigation. Eur J Pharm Biopharm 2012;82:139-150.

170 Sahle FF, Metz H, Wohlrab J, Neubert RH: Lecithin-based microemulsions for targeted delivery of ceramide AP into the stratum corneum: formulation, characterizations, and in vitro release and penetration studies. Pharm Res 2013;30:538-551.
171 Gregoire S, Patouillet C, Noe C, Fossa I, Kieffer FB, Ribaud C: Improvement of the experimental setup for skin absorption screening studies with reconstructed skin EPISKIN. Skin Pharmacol Phys 2008;21:8997.

172 Tokudome Y, Uchida R, Yokote T, Todo H, Hada N, Kon T, Yasuda J, Hayashi H, Hashimoto F, Sugibayashi K: Effect of topically applied sphingomyelin-based liposomes on the ceramide level in a three-dimensional cultured human skin model. J Liposome Res 2010;20:49-54.

173 Tokudome Y, Jinno M, Todo H, Kon T, Sugibayashi $\mathrm{K}$, Hashimoto F: Increase in ceramide level after application of various sizes of sphingomyelin liposomes to a cultured human skin model. Skin Pharmacol Phys 2011;24:218-223.

174 Asai S, Miyachi H: Evaluation of skin-moisturizing effects of oral or percutaneous use of plant ceramides (in Japanese). Rinsho Byori 2007;55:209-215.

175 Shimada E, Aida K, Sugawara T, Hirata T: Inhibitory effect of topical maize glucosylceramide on skin photoaging in UVA-irradiated hairless mice. J Oleo Sci 2011;60:321325.
176 Grob CA, Jenny EF: Die synthese von dihydro-sphingosin. Helv Chim Acta 1952;35: 2106-2111.

177 Carter HE, Shapiro D, Harrison JB: Synthesis and configuration of dihydrosphingosine. J Am Chem Soc 1953;75:1007-1008.

178 Fujino Y, Negishi T: Studies on the conjugated lipids. 5. Configuration of the galactoside linkage in cerebrosides. Bull Agric Chem Soc Japan 1956;20:183-187.

179 Carter HE, Nalbandov O, Tavormina PA: Biochemistry of the sphingolipides. 6 . The O-methyl ethers of sphingosine. J Biol Chem 1951;192:197-207.

180 Karlsson KA: On the chemistry and occurrence of sphingolipid long-chain bases. Chem Phys Lipids 1970;5:6-43.

181 Sambasivarao K, McCluer RH: Thin-layer chromatographic separation of sphingosine and related bases. J Lipid Res 1963;4:106108.

182 Gatt S: Enzymic hydrolysis of sphingolipids - hydrolysis of ceramide glucoside by an enzyme from ox brain. Biochem J 1966;101: 687-691.

183 Gatt S, Rapport MM: Enzymic hydrolysis of sphingolipids - hydrolysis of ceramide lactoside by an enzyme from rat brain. Biochem J 1966;101:680-686. 